THE ROLE OF TEACHER EFFICACY SOURCES FOR GENERAL EDUCATION TEACHERS WITH SPECIAL EDUCATION INCLUSION CLASSROOMS

\author{
A Dissertation \\ Presented to the Faculty of the Curry School of Education \\ University of Virginia \\ In Partial Fulfillment \\ Of the Requirements for the Degree \\ Doctor of Education \\ By \\ Elizabeth Muller Beaty, B.S., M.Ed.
}

May 2015 
CCopyright by

Elizabeth Muller Beaty

All Rights Reserved

May 2015 


\begin{abstract}
Advisor: Dr. Dennise Berry

The purpose of this study was to determine if the frequency of experiences theorized as efficacy sources correlated to differences in levels of general education teachers' efficacy regarding students with disabilities.

Students with disabilities have been spending an increasing portion of the instructional day in the general education classroom. This is due to federal laws and court cases that have evolved since the 1970s when the first law that guaranteed a free and appropriate public education for all children was passed. However, general education teachers report feeling that they lack to skills and competencies necessary to meet the educational needs of these students. This suggests that general education teachers have lower teaching efficacy concerning students with disabilities, which may negatively affect the academic achievement of these students. Teaching efficacy is a variable that has been associated with academic achievement.

To achieve the purpose of this study survey methodology was employed and descriptive and correlational data was derived. The sample population of this study was general education teachers who had students with disabilities in their class from 40 elementary schools in a large, suburban school district. The unit of analysis for this study was the individual teacher. The 21 item survey for this study had two parts. The first part included the Teacher Efficacy Scale (Dembo \& Gibson, 1984) amended to reflect students with disabilities. The second part of the survey included researcher generated questions based on the four efficacy sources identified by Bandura (1977) and
\end{abstract}


professional development literature. Additionally, participants were asked to quantify how many years they had students with disabilities in their class in the past ten years.

Correlational data indicated that years of experience correlated to the frequency of mastery experiences and vicarious experiences. Analysis of covariance revealed that the frequency of mastery experiences was significantly related $(p<.05)$ to differences in general education teachers' efficacy regarding students with disabilities. However, the frequency of vicarious experiences was not significantly related $(p<.05)$ to differences in general education teachers' efficacy regarding students with disabilities. Because there was no correlation between years of experience and social persuasion experiences, analysis of covariance was used to analyze that data. Even when years of experience were controlled for, the frequency of social persuasion experiences was not significantly related $(p<.05)$ to differences in general education teachers' efficacy regarding students with disabilities.

Implications for practice and recommendations for future research were discussed, including conducting qualitative research on the nature of mastery experiences that affect general teachers' efficacy regarding students with disabilities, using different measures of teaching efficacy to explore the relationship between the frequency of efficacy source experiences and teaching efficacy concerning students with disabilities, and expanding the sample size to support the validity of this study's findings. 


\section{DEDICATION}

To my three beautiful daughters, Emily, Kathleen and Meg: Your encouragement, love, and laughter have carried me through.

To Tim: Thank you for your unwavering support, your interest in my work, and your love. I couldn't have crossed the finish line without your help.

To Dad and Bridget: Thank you for always showing up, for believing in me, and for being my family.

And in loving memory of Danny and Mom. 


\section{ACKNOWLEDGEMENTS}

Dr. Denny Berry, my advisor, agreed to be my chair even though she already had heaps on her plate. You have a good heart, Denny! Thank you for challenging me, for inspiring me with your scholarship and knowledge, and for always having my back. It has been such a pleasure (or at least as much of a pleasure as dissertation writing can be) to work with you. Thank you for all your time, effort and valuable feedback.

Dr. Jim Esposito agreed to be my chair through the defense of the proposal. He did this for me out of kindness, and as he was entering his much deserved retirement. Dr. Esposito, thank you for your belief in me, for your patience, and for leading me to really think. It meant more to me than you might ever know.

Dr. Elizabeth Potts also deserves my acknowledgment. She reminded me of why working with students with special needs has always been my passion. Dr. Potts, thank you for reading my work with care and patience and for always giving me thorough and detailed feedback.

I would also like to acknowledge the staff and students of Union Mill Elementary. They have been my constant cheerleaders and supporters. Finally, to my dear friends who have believed in me since I started this journey (you know who you are), thank you from the bottom of my heart. 
TABLE OF CONTENTS

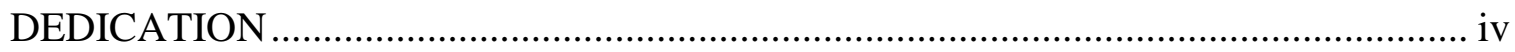

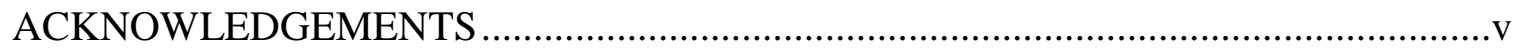

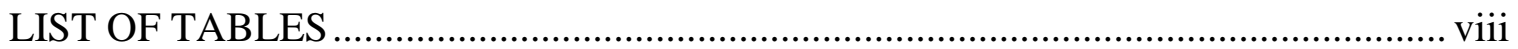

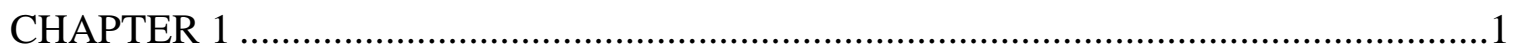

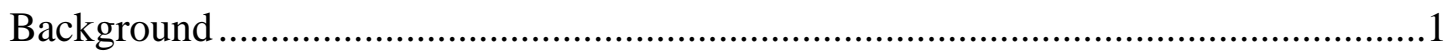

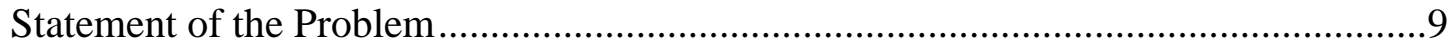

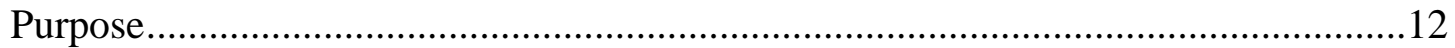

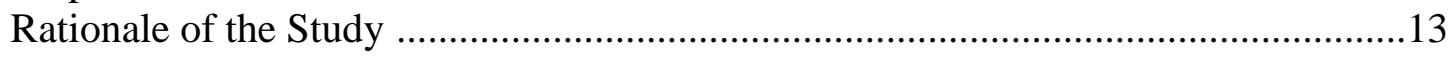

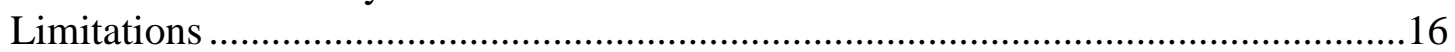

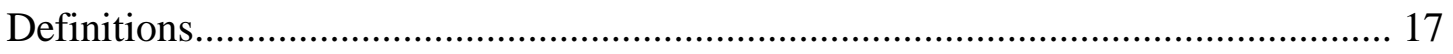

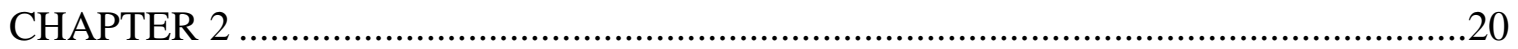

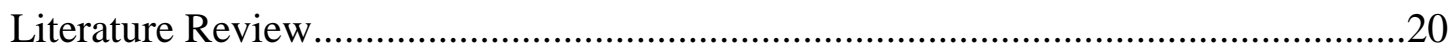

Inclusion History and Research ............................................................21

Conceptual Framework of Teacher Efficacy ...............................................27

Instructional Practices Associated with Teacher Efficacy ................................... 31

Instructional Practices Associated with Student Achievement...............................34

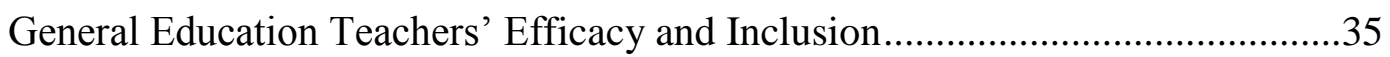

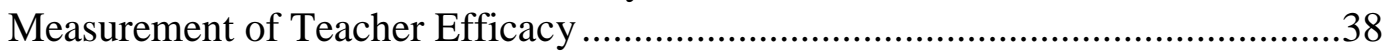

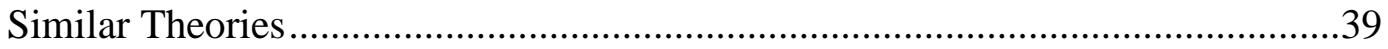

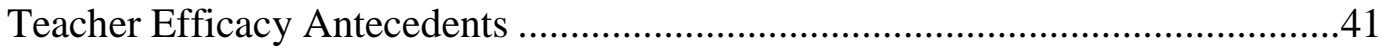

Experiences as Sources of Teaching Efficacy ......................................41

Professional Development as Source of Teaching Efficacy .....................45

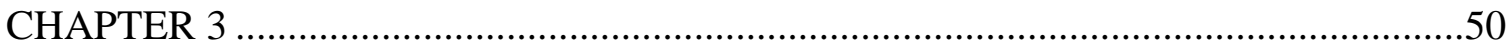

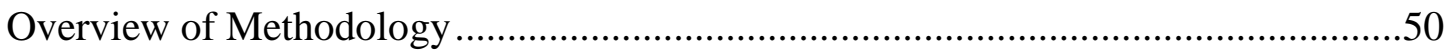

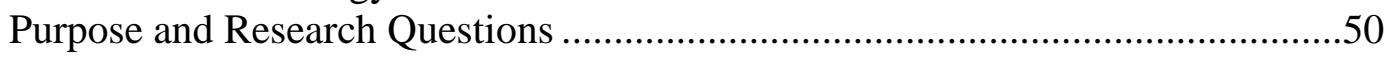

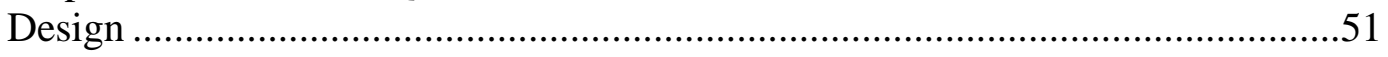

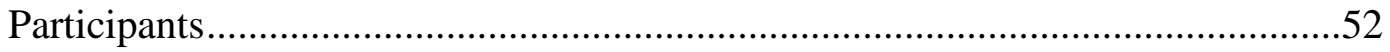

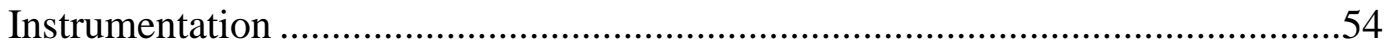

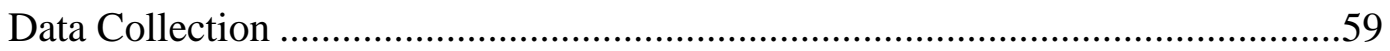

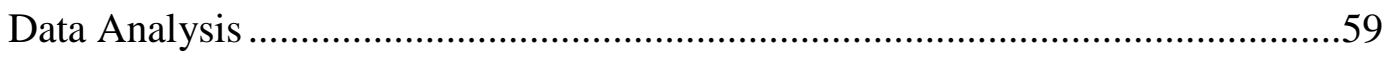

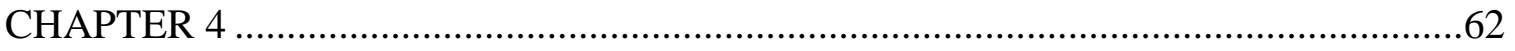

Presentation and Analysis of the Data

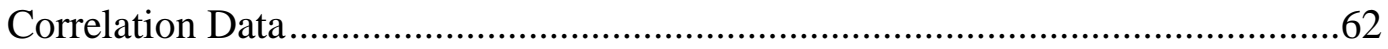

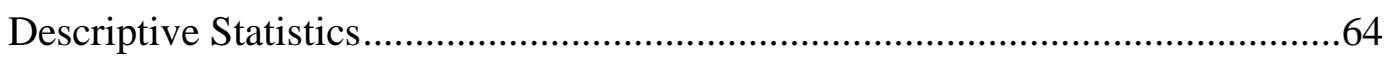

One-way Analysis of Variance -Mastery Experiences and Efficacy ....................67 


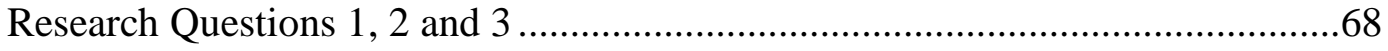

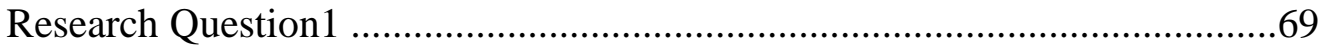

Research Question 2 ..........................................................................

Research Question 3 ................................................................................ 70

One-way Analysis of Variance - Vicarious Experiences and Efficacy..................71

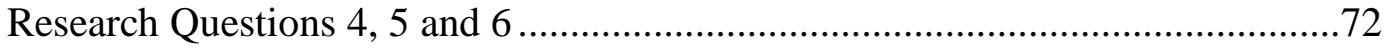

Research Question 4 ...............................................................................73

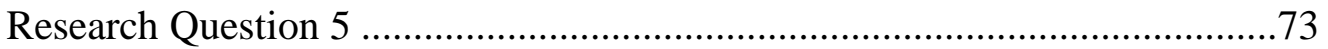

Research Question 6 .................................................................................

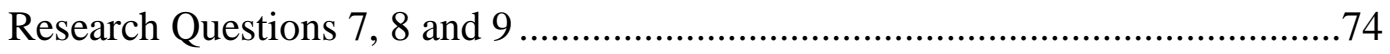

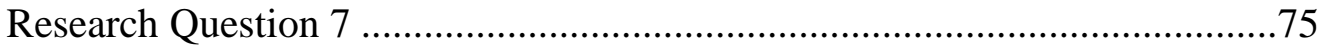

Research Question 8 ...............................................................................

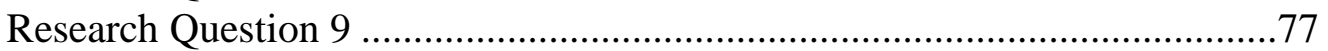

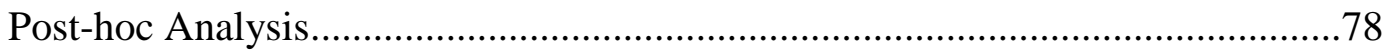

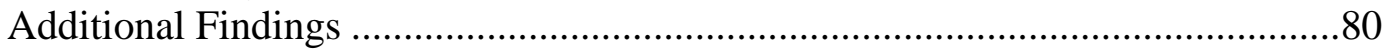

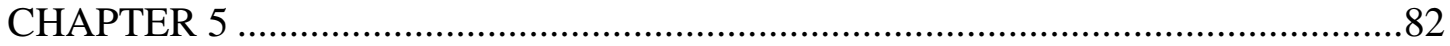

Summary, Discussion of Findings, and Conclusions

Review of the Purpose, Problem and Rationale..............................................82

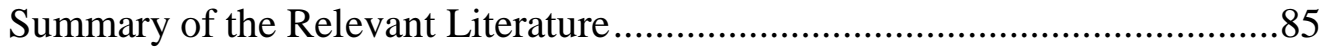

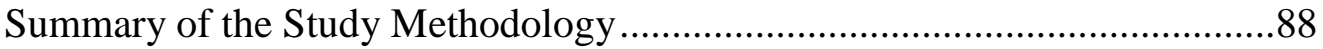

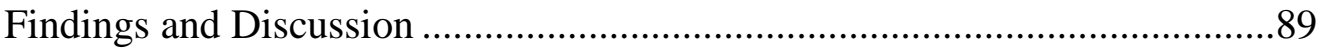

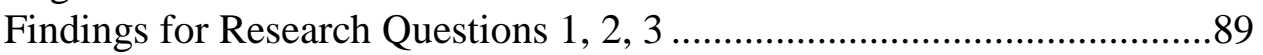

Findings for Research Questions 4, 5, 6 .............................................90

Findings for Research Questions 7, 8, 9 ................................................91

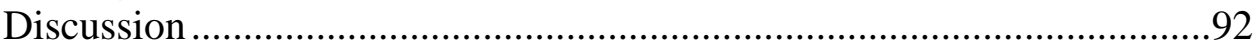

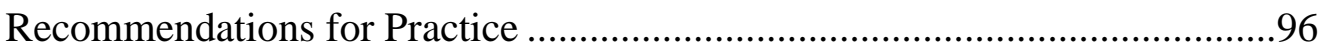

Recommendations for Future Research ........................................................97

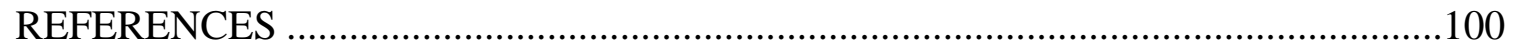

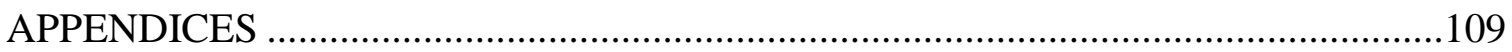




\section{LIST OF TABLES}

TABLE

1. Factor Loading and Coding of Teacher Efficacy Scale Survey Items...........................56

2. Independent Variable- Expert Sources of Validity ......................................................58

3. Correlation between Mastery Experiences and Years of Experience ............................63

4. Correlation between Vicarious Experiences and Years of Experience .........................63

5. Correlation between Social persuasion Experiences and Years of Experience ............63

6. Descriptive Statistics for Independent Variable: Frequency with which Respondents have Participated in Mastery and Vicarious Experiences .................64

7. Frequencies of Mastery Experiences ………………………...............................65

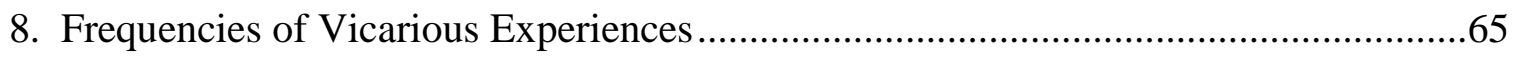

9. Frequencies of Social Persuasion Experiences ............................................................66

10. Descriptive Statistics for Dependent Variable: Efficacy Beliefs Concerning Students with Disabilities

11. One-Way Analysis of Variance: Frequency of Mastery Experiences and Efficacy - Descriptive Statistics

12. One-Way Analysis of Variance: Frequency of Mastery Experiences and Efficacy.....

13. One-Way Analysis of Variance: Frequency of Vicarious Experiences and Efficacy - Descriptive Statistics 
14. One-Way Analysis of Variance: Frequency of Social Persuasion Experiences and Efficacy ................................................................................................

15. Results of the ANCOVA for Personal Teaching Efficacy (Social Persuasion).......... 75

16. Results of the ANCOVA for General Teaching Efficacy (Social Persuasion)........... 76

17. Results of the ANCOVA for Total Teaching Efficacy (Social Persuasion) ............... 77

18. Post-hoc Comparison Using the Scheffe Test ………………….............................79 


\section{Chapter 1}

\section{Background}

Changes in federal laws over the past 40 years have altered the nature of the students placed in the general education classroom. Increasingly, school districts are using an inclusion model, in which students with disabilities receive the majority of their special education services in the general education classroom. Inclusion is based on a philosophy or belief that all students can learn and achieve (Salisbury, Streiker, Roach, \& McGregor, 2001). An inclusion model of delivering special education services to students with disabilities includes the following components: (a) students with disabilities attend their neighborhood or base school; (b) educational placement of students with disabilities is with age- and grade-appropriate peers; and (c) special education support takes place within the general education classroom for a portion or a majority of the school day (Sailor, 1991; Salisbury et al., 2001).

A service delivery model for students with disabilities based on a philosophy of inclusion is a change from the way students with disabilities have previously been educated in public schools. To understand the focus on inclusion today, it is necessary to understand the changes in federal laws and public policy brought about by court cases in the 1970s. When first addressed, issues about the education of students with disabilities arose out of concerns surrounding access to public education. 
As recently as the 1970s, students with disabilities were often totally excluded from public schools. Before 1975, a school district could deny admission to a student with a disability based on the severity of the disability and on the belief that segregation of these students was appropriate (Itkonen, 2007).

During the 1970s, parents who were attempting to gain access to public education for their children with special needs initiated several court cases. The ruling in these cases, often referred to as "right-to-education" lawsuits (Itkonen, 2007), established that denying a student access to schooling was a violation of the due process provisions of the Constitution. In two cases, the Pennsylvania Association of Retarded Citizens (PARC) vs. Commonwealth of Pennsylvania and Mills vs. Board of Education, the court ruled in favor of parents who were attempting to gain access to public education for their children with disabilities (Itkonen, 2007; Koegh, 2007). In the 1971 Pennsylvania Association of Retarded Citizens (PARC) vs. Commonwealth of Pennsylvania case, the courts struck down a state statute that allowed schools to deny admittance to students who had not reached the mental age of five. Similarly, in the 1972 Mills vs. Board of Education case, seven students with disabilities successfully brought suit against the District of Columbia for denying admittance or expelling students solely on the basis of their disability (Martin, Martin, \& Terman, 1996).

Despite these court rulings, state policies in the early 1970s regarding access to public education for students with disabilities still varied widely. The disability advocacy community therefore began to appeal to Congress to pass federal legislation regarding special education. A strong political consensus developed, and PL 94-142, or the Education for all Handicapped Children law, passed with little opposition in 1975. 
Passage of this law effectively abolished institutionalized exclusion from public education of any student based on the nature or severity of their disability (Itkonen, 2007).

The Education for All Handicapped Children Act changed the lives of students with disabilities and their families. It was, in fact, a civil rights law that ensured access to a free and appropriate public education for all children (Itkonen, 2007).

The act stipulated that every child with a disability had the right to a free and appropriate public education, and educational services were to occur in the least restrictive environment. The mandate for educating students in the least restrictive environment meant that students with disabilities were to be educated with their typically developing peers, or their peers without disabilities, to the greatest extent possible (Damer, 2001). Districts had to provide a continuum of services, and placement decisions for students with disabilities had to be both appropriate and provided in the least restrictive environment. A student with a disability could be removed from the general education classroom only after modifications to that educational setting had been attempted first (Martin et al., 1996).

The least restrictive provisions of PL 94-142, later renamed the Individuals with Disabilities in Education Act (IDEA) gave rise to the practice of "mainstreaming." With mainstreaming, students with disabilities were in the general education classroom for subjects such as music, physical education, and art, but they received their academic instruction in a self-contained classroom with a special education teacher. The practice of mainstreaming continued in this manner into the late 1980s (Damer, 2001). 
Towards the middle of the same decade, the regular education initiative movement lobbied for the reinterpretation of the least restrictive environment. The regular education initiative, first introduced by Madeline Will, former secretary of Education, in 1986, proposed a merging of special education and general education services into a unitary system (Harkins, 2012). The concerns of the regular education initiative movement focused on the idea that special education placements did not provide the least restrictive environment for students with disabilities. The regular education initiative eventually became known as the inclusion movement. This movement, based on the inclusion philosophy, asserted that students with disabilities should spend the majority of their day in the general education classroom (Damer, 2001).

By the end of the 1980s, states had implemented the federal policies regarding special education. The focus of the 1970s and 1980s had been on gaining access to public education for students with disabilities. However, the decade of the 1990s saw a shift in focus towards measurable outcomes through standards-based reforms and increased accountability measures in general education, as well as special education.

According to Itkonen (2007), this change in focus towards outcomes and accountability grew out of Goals 2000, a policy enacted by Congress encouraging states to adopt standards for both content and performance. In 1994, the Improving America's Schools Act, a reauthorization of the Elementary and Secondary Education Act, passed. This law required states, in order to receive Title I funding, to submit plans for developing high standards for content and performance, as well as plans for developing assessments to measure if students were meeting those standards. This movement towards accountability began to evolve in special education at this time, as well. 
Congress amended the Education of All Handicapped Children Act in 1990 and renamed it the Individuals with Disabilities in Education Act (IDEA) or PL 101-476. This law changed all references to "handicapped children" to "children with disabilities." States were provided with funding for the education of students with disabilities if the requirements of IDEA were met (Harkins, 2012).

Shortly thereafter, in 1994, the courts upheld the policy of inclusion. In Holland v. Sacramento Unified School District, the court's decision stated that when students with disabilities are in a school setting, the starting point for placement decisions should always be the general education classroom. The inclusion movement resulted in fewer pull-out programs for students with disabilities; instead, the special education teacher became a team member with the general education teacher, sharing responsibilities for planning lessons, delivering services, and monitoring progress (Damer, 2001).

In 1997, Congress passed amendments to IDEA. These amendments required that a general education teacher be present at the individualized education plan (IEP) meeting for each student with a disability, increasing the accountability of general education teachers for the progress of students with disabilities in their class. The 1997 reauthorization provisions also required participation of students with disabilities in statewide assessments (Itkonen, 2007). Prior to 1997, students with disabilities were not required to participate in statewide assessment systems (Thurlow, Lazurus, Thompson, \& Morse, 2005). In addition to requiring students with disabilities to participate in accountability assessments, the 1997 amendments required states to provide accommodations when appropriate for these students when taking these tests, to report 
the participation rate of students with disabilities in state assessments, and to report the performance of these students on those assessments (Thurlow et al., 2005).

In 2001, the reauthorization of the federal Elementary and Secondary Education Act passed and became known as No Child Left Behind (NCLB). This law required greater accountability on the part of schools because it stipulated the use of researchbased instructional strategies and interventions, and it increased the focus on the academic achievement of all students, especially in literacy and math (Bouck, 2009). Taking state tests in reading and math are now common requirements for both students with disabilities and their general education peers.

The change to more of an inclusion model is due in part to the reauthorization of the IDEA in 1997 and in 2004 and NCLB in 2001 (Bouck, 2009). The thinking was that since students with disabilities had to take the high-stakes, state-mandated tests aligned to grade level curriculum, they had to have access to the general education curriculum, and this, along with changes in federal laws, resulted in an increase in the use of the inclusion model of service delivery for students with disabilities.

One manner of implementing inclusion has been to use a co-teaching model in the general education classroom. According to Friend, Cook, Hurley-Chamberlain, and Shamberger (2010), co-teaching — in which a special education teacher and a general education teacher team up to provide access to the general education curriculum for the student with disabilities and to provide the necessary special education accommodations and services in the general education classroom — also became more widely used as a result of the new policies and federal laws. Implementing co-teaching is a way that school districts attempted to achieve the mandates of No Child Left Behind and to 
provide the least restrictive environment for students with disabilities. Co-teaching allows students with disabilities to remain in the general education classroom for the majority of the instructional day and still receive special education services when the special education teacher is in the room.

Additionally, Friend et al. (2010) identified different ways that co-teaching is implemented in the classroom. The various co-teaching approaches include the following: one teaches, one assists: one teaches, one observes; station teaching, where each teacher teaches a small group; parallel teaching, where the class is divided in half and each teacher teaches one group; alternative teaching, where one teacher takes a small group and the other teacher works with the large group; and teaming where both teachers alternate to instruct the large group together. The special education teacher and general education teacher change their role depending on what approach is being utilized. There may be times, however, when the special education teacher is not in the room, and the general education teacher must provide instruction for students with disabilities in her class without assistance.

As a result of changes in federal laws and historical shifts in the field of special education, students with disabilities are spending more of the day in the general education classroom. Since $2006,57 \%$ of students with disabilities have spent more than $80 \%$ of their day in the general education classroom (U.S. Department of Education, Office of Special Education and Rehabilitative Services, 2010). Increasingly, general education teachers have students with disabilities in their classrooms for the majority of the instructional day, and they are responsible for ensuring the academic achievement of 
these students in the grade level curriculum, as well as their success on high-stakes, statemandated tests.

The majority of general education teachers support the idea of inclusion, in theory, but they are not as likely to believe they have the necessary skills to meet the needs of students with disabilities placed in their classrooms (Scruggs \& Mastropieri, 1996; Smith \& Tyler, 2011). Sixty-five percent of general education teachers report that they favor inclusion of students with disabilities, but only $29.2 \%$ say they have adequate training and expertise to meet the needs of these students in their classrooms (Scruggs \& Mastropieri, 1996). General education teachers report a lack of training regarding teaching students with disabilities (deBettecourt, 1999). Most general education teachers took one Exceptionalities course, which was the extent of their preparation for teaching students with disabilities in inclusion settings (Yellin et al., 2003). Typically, an Exceptionalities college class focuses on the characteristics of students who learn and behave in ways that are outside the norm and covers such issues as identification and classification of individuals with disabilities. However, it does not typically include specific instructional strategies for teaching students with different types of disabilities.

As a result of this lack of training, general education teachers have lower confidence in their abilities to implement inclusion than special education teachers do (Coladarci \& Breton, 1997; deBettencourt, 1999; Shippen et al., 2011). Special education teachers have taken more courses that examine the nature of students with disabilities and methods for teaching them, which could explain the differences in confidence between general education teachers and special education teachers in regards to inclusion (deBettencourt, 1999). General education teacher perceptions of inclusion 
affect the academic success of students with disabilities in their class because these perceptions are directly related to the accommodations that teachers are willing and able to provide for these students in the general education classroom (Ysseldyke, Thurlow, Christenson, \& McVicar, 1988).

General education teachers often see challenging behaviors of students with disabilities as beyond their influence. They perceive that these students require special instructional approaches and that they lack the expertise to teach such children effectively. When general education teachers hold beliefs that the characteristics of children with disabilities are fixed traits, rather than changeable behaviors, then they undermine their own ability to teach these students effectively (Hollenweger, 2011). Because of their perceived lack of adequate training and expertise, general education teachers report being frustrated with inclusion. This frustration negatively affects the quality of their instructional practice in classrooms that include students with disabilities (deBettencourt, 1999; Kilanowski-Press, Foote, \& Rinaldo, 2010;). The reported lack of necessary training and specific skills needed by general education teachers to teach students with disabilities may also lead to beliefs which result in certain teacher behaviors that can affect the achievement of these students.

\section{Statement of the Problem}

This study was based on research that found that the majority of general education teachers do not feel qualified or competent to teach students with disabilities (deBettencourt, 1999; Grskovic \& Trzcinka, 2011 Scruggs \& Mastropieri, 1996; Smith \& Tyler, 2011;). Increasing numbers of students with disabilities are spending more of their day in the general education classroom, and general education teachers are uncertain of 
their ability to meet the needs of these students (Buell, Hallam, Gamel-McCormick, \& Sheer, 1999). These beliefs, based on a perceived lack of training and self- competence, then lead to certain teacher behaviors.

The literature repeatedly shows a relationship between teachers' sense of teaching efficacy, which is a belief, and their behaviors related to students with disabilities (Ashton \& Webb, 1986; Dembo \& Gibson, 1985; Dibapile, 2012; Gibson \& Dembo, 1984). For example, teacher efficacy impacts a general education teacher's attitudes about inclusion of students with disabilities in the general education classroom and resulting teacher behaviors (Gao \& Mager, 2011; Kosko \& Wilkins, 2009; Soodak \& Podell, 1993; Soodak, Podell \& Lehman, 1998). Teacher efficacy impacts behaviors like the amount of time a teacher spends preparing lessons and the instructional methods chosen by the teacher (Gotshall \& Stefanou, 2011). Those with high teacher efficacy are more likely to believe that all students can learn (Ashton \& Webb, 1986) and more likely to exhibit perseverance with students who are struggling academically (TschannenMoran, Woolfolk Hoy, \& Hoy, 1998).

There is a significant gap between the academic achievement of students with disabilities and the achievement of their general education peers on state-mandated tests. Differences between these two subgroups can be "more than 30 to 40 percentage points" in reading and math, although this varies from state to state (Center on Education Policy, 2009).

The literature also identifies teacher efficacy, again a belief, as an important construct tied to student achievement (Ashton \& Webb, 1985; Tschannen-Moran, et al., 1998; Wentzel \& Wigfield, 1998). Teaching efficacy refers to a teacher's belief that she 
has the capabilities to bring about change in her students, even when those students are struggling academically. A teacher with high teaching efficacy believes that what he or she does affects a student over and above outside factors such as home environment, cognitive abilities, and socioeconomic status.

Teacher efficacy influences the instructional decisions that teachers make which, in turn, impacts student achievement (Wentzel \& Wigfield, 1998). For example, teachers with high teaching efficacy are more likely to greet students at the door, to walk around the room while students are working independently, and to praise students more often (Ashton \& Webb, 1986). They are also more likely to implement new ideas, put more effort into teaching, and to set higher goals for themselves and their students (TschannenMoran et al., 1998). Teacher efficacy beliefs impact teacher behaviors surrounding student-teacher relationships, classroom management strategies, and instructional choices, all of which have an impact on student achievement (Ashton \& Webb, 1986).

Bandura (1998) theorized that teaching efficacy, based on his original theory of self-efficacy (Bandura, 1977), can be changed through four types of experiences. These experiences include: mastery experiences, vicarious experiences, social persuasion experiences, and affective state experiences. For teachers, mastery experiences would be successful practices and performances in the classroom, while vicarious experiences refer to those in which a teacher observes another modeling successful teaching practice. Social persuasion experiences include positive feedback from a respected other; coursework is also a type of social persuasion experience. Finally, affective state experiences refer to the ways in which a teacher responds to his or her own levels of stress or anxiety about teaching (Bautista, 2011). 
Additionally, Gibson and Dembo (1984) identified two types of teaching efficacy. Personal teaching efficacy is the belief that a teacher, herself, has the skills and competencies to bring about change in her students. General teaching efficacy is the belief that, in general, teachers can have an impact on their students over and above outside factors, such as the cognitive abilities and the home environment of their students.

Knowing what experiences contribute to higher teacher efficacy concerning students with disabilities could lead to more focused training and professional development opportunities. These experiences, if based on theorized sources of teacher efficacy, could help increase the teaching efficacy of general education teachers concerning students with disabilities. Increasing their teaching efficacy, which the literature shows can lead to changes in teacher behaviors that are associated with increased academic achievement, may help to close the gap between the achievement of students with disabilities and their peers.

\section{Purpose}

The purpose of this study was to determine if the frequency with which general education teachers have had experiences identified by Bandura as efficacy sources is related to differences in their teaching efficacy concerning students with disabilities. As previously noted, Bandura's theory (1977) suggests that certain experiences (mastery, vicarious, social persuasion, and affective state) contribute to higher levels of efficacy. In order to achieve the purpose of this study, the following research questions were asked: 
1. Are differences in the frequency of mastery experiences related to differences in personal teaching efficacy?

2. Are differences in the frequency of mastery experiences related to differences in general teaching efficacy?

3. Are differences in the frequency of mastery experiences related to differences in total teaching efficacy?

4. Are differences in the frequency of vicarious experiences related to differences in personal teaching efficacy?

5. Are differences in the frequency of vicarious experiences related to differences in general teaching efficacy?

6. Are differences in the frequency of vicarious experiences related to differences in total teaching efficacy?

7. Are differences in the frequency of social persuasion experiences related to difference in personal teaching efficacy?

8. Are differences in the frequency of social persuasion experiences related to differences in general teaching efficacy?

9. Are differences in the frequency of social persuasion experiences related to differences in total efficacy?

\section{Rationale of the Study}

The measurement by school districts of the achievement of all students has been a result of the move towards further accountability in education. As noted before, there is a documented 30-40\% gap between the achievement of students with disabilities and their general education peers (Center on Education Policy, 2009). Federal and state legislation 
and policies have mandated closing achievement gaps between different subgroups, one of which is students with disabilities (NCLB, 2001).

In order to close the gap and increase achievement for students with disabilities, the literature suggests numerous pathways including a focus on teacher beliefs and behaviors. Certain teacher behaviors have been associated with increased student achievement. When teachers build relationships with students, and praise them more often, achievement is improved (Wentzel \& Wigfield, 1998). When they engage in certain instructional strategies, like spending more time on lesson preparation and persevering with struggling students, students in their class achieve at higher levels (Ashton \& Webb, 1986; Dembo \& Gibson, 1985; Dibapile, 2012). Additionally, when students have high self-efficacy themselves, which is impacted by their teacher's teaching efficacy level (Bandura, 1993) they are more likely to achieve academically (Wentzel \& Wigfield, 1998). These same behaviors are associated with the beliefs of those with high teacher efficacy.

The teacher behaviors affecting the academic achievement of students with disabilities are similar — they also include teacher choices about instructional strategies, interpersonal interactions with students, and curricular materials, as well as the ability to collaborate with both parents and colleagues (Whitley, 2010). When teachers provide small group instruction, their students with disabilities achieve at higher levels. When they provide supervised independent practice, their students with disabilities are more likely to experience academic success (McLeskey \& Waldron, 2011). When general education teachers collaborate with their colleagues and the parents of their students, inclusion is more successful (Coldarci \& Breton, 1997). This ability of the general 
education teacher to collaborate with the special education teacher is a prerequisite for successful implementation of a co-teaching approach in an inclusive classroom (Fuchs, Fuchs, Craddock, Hollenbeck, \& Hamlett, 2008). Again, these same teacher behaviors linked to the academic achievement of students with disabilities are associated with the beliefs of those with high teacher efficacy.

Because high teacher efficacy has been associated with increased student achievement, and currently there is a gap between the achievement of students with disabilities and their general education peers, research needs to be done in this area; as Klasson, Tze, Betts, and Gordon (2011, p. 39) put it, "research on the sources of efficacy will lay the groundwork for the application of theory to practice."

As previously noted, Bandura (1977) suggested that four types of experiences act as sources of efficacy: mastery experiences, vicarious experiences, social persuasion experiences, and affective state experiences. Mastery experiences refer to those experiences in which a teacher has had success with a student. Vicarious experiences are those in which a teacher has observed another having success with a student. Social persuasion experiences are those in which a teacher receives verbal feedback or praise from another. Finally, affective state experiences refer to the level of stress or excitement that a teacher feels when working with students.

Some research has attempted to define specifically what these kinds of experiences are and how they impact teaching efficacy (Bautista, 2011). However, a review of the literature shows very little research that tests whether the experiences that Bandura identified as affecting efficacy actually do so for teachers (Klasson, et al., 2011). Determining whether there is a relationship between different types of experiences, based 
on Bandura's efficacy sources, and general education teacher efficacy concerning students with disabilities is an area in which more research needs to be done.

Increasing teacher efficacy appears to be one pathway for developing the competencies and skills necessary for improving instructional practices (Dembo \& Gibson, 1985; Dibapile, 2012; Gibson \& Dembo, 1984; Gotshall \& Stefanou, 2011; Tschannen-Moran et al., 1998) that then lead to higher student achievement. In particular, the literature points out that general education teachers may not have the levels of teaching efficacy needed to positively affect the academic achievement of students with disabilities in their class (Coladarci \& Breton, 1997; deBettencourt, 1999; Hollenweger, 2011; Shippen et al., 2011).

This study could give further validity to the theory that states that certain experiences impact teaching efficacy. Additionally, it could inform decisions about professional development opportunities and training for general education teachers who have the responsibility for working with students with disabilities in the general education setting.

\section{Limitations}

This study has several limitations:

- One large school division was used in this study as the population. Results of the study cannot be generalized to other populations.

- The response rate for this study was low, due in part to the manner in which the division required the survey to be sent out.

- The survey results were based on teacher self-report which has inherent possible error. 
- The definitions of the terms, along with the definitions and examples used for the survey questions measuring the frequency of each experience, were researcher generated and may have impacted the results of this study.

- The use of the Teacher Efficacy Scale (Gibson \& Dembo, 1984) rather than another measure of teacher efficacy may have impacted the results of the study.

- The researcher generated quartiles used to get a representative sample and based on free and reduced lunch/fees for each elementary school in the division may have impacted the study results.

- Other variables not controlled for may have impacted the survey results.

\section{Definitions}

For the purpose of this study the following definitions were used:

Affective state experiences: Affective state experiences are defined as those that impact a teacher's level of anxiety or excitement. Some ways to regulate affective state include attribution, relaxation and use of biofeedback, symbolic desensitization, and symbolic exposure (Bandura, 1977). For the purposes of this study, affective state experiences refer to teacher perceptions of their anxiety or excitement about working with students with disabilities.

General Teaching Efficacy: General teaching efficacy is defined as a teacher's overall sense of teaching efficacy (Dembo \& Gibson, 1985), which includes a belief that teachers in general have a capacity to effect change in students over and above outside factors such as family background, parental influence, and home environment. General teaching efficacy was measured by the eight items on the shortened version of the Teacher 
Efficacy Scale that are factored loaded on general teaching efficacy (Ashton \& Webb, 1983; Gibson \& Dembo, 1984).

Inclusion: For the purposes of this study, inclusion is defined as a philosophy that includes the belief that all students belong in the general education classroom and all can learn. Inclusion brings special education services and support to the general education classroom, as opposed to removing students to a special classroom. Inclusion means that students are not removed from their age- or grade-level peers, but instead receive the majority of their instruction in the general education classroom (Kilanowski-Press et al., 2010).

Mastery/enactive experiences: Mastery experiences or performance accomplishments are defined as activities that include participant modeling (the environment is structured so that a person experiences success despite their weaknesses), performance desensitization, performance exposure, and self-instructed performance (Bandura, 1977). Professional development experiences in the mastery category, for the purposes of this study, will include previous successful experiences working with students with disabilities.

Personal Teaching Efficacy: Personal teaching efficacy is defined as a teacher's beliefs about his or her own personal ability to motivate students to learn and to impact change. It will be measured by the eight items on the shortened version of the Teacher Efficacy Scale that are factored loaded on personal teaching efficacy (Ashton \& Webb, 1983;

Gibson \& Dembo, 1984).

Professional Development: For the purpose of this study, professional development is defined as in-service training to increase content and pedagogical knowledge of teachers 
in order to improve instructional practice and student learning. Professional development includes job embedded training, coaching, professional workshops, and collaborative work with teacher teams.

Students with Disabilities: Students with disabilities are defined as students with current IEPs.

Teacher Efficacy: Teacher efficacy is a belief that one has the skills and abilities necessary to bring about student learning. Teacher efficacy, in this study, is defined as the total score on the Teacher Efficacy Scale (Gibson \& Dembo,1984).

Verbal/Social Persuasion Experiences: Social persuasion experiences are defined as activities that include suggestion, exhortation, and self-instruction (Bandura, 1977). Professional development experiences in the social persuasion category, for the purposes of this study, will include peer coaching (Joyce \& Showers, 2002), participation in a study group that collaboratively examines current research (Darling-Hammond \& Richardson, 2009), as well as course work and professional development training about students with disabilities.

Vicarious experiences: Vicarious experiences are defined as activities that include live modeling (observing another teacher teaching) and symbolic modeling (imagining oneself engaging in teaching) (Bandura, 1977). Professional development experiences in the vicarious experience category, for the purposes of this study, will include analysis of student work and student data in collaborative teams and peer observation of practice (collaborative learning visits) (Darling-Hammond \& Richardson, 2009). 


\section{Chapter 2}

\section{Literature Review}

This study draws from the literature in the following areas: 1) inclusion history and research; 2) theoretical concepts underlying teacher efficacy; 3) instructional practices associated with teacher efficacy; 4) instructional practices associated with student achievement; 5) general education teachers' efficacy and inclusion; 6) measurement of teacher efficacy; 7) similar theories, and; 8) antecedents of teacher efficacy.

The first section of the literature review summarizes the legislative and legal mandates that led to greater inclusion of students with disabilities in the general education classroom. Additionally, literature that explores the outcomes of inclusion for students with disabilities is included in this section.

The second section presents the work of Rotter (1966) and Bandura (1977) and other relevant literature regarding the theoretical foundations of teacher efficacy (Ashton \& Webb, 1986; Bandura, 1977; Tschannen-Moran, Woolfolk-Hoy \& Hoy, 1998). Included in the third, fourth, and fifth sections is the literature on beliefs and resulting teacher behaviors associated with teacher efficacy and their relationship to student achievement. Literature that specifically examines general education teacher behaviors associated with teacher efficacy and concerning students with disabilities is included.

The sixth section includes the literature on the Teacher Efficacy Scale (Gibson \& Dembo, 1984), one instrument that measures teacher efficacy. The seventh section examines 
literature on current popular theories that have their inception in the concept of efficacy, and have been applied to teaching and learning (Duckworth, Peterson, Mathews, \& Kelly, 2007; Dweck, 2006). Finally, the last section presents literature pertaining to possible sources of efficacy. Included in this section is literature surrounding experiences and professional development as pathways to changing teacher efficacy.

\section{Inclusion History and Research}

The relatively brief history of the field of special education gives a unique perspective on the school reform movement and the resulting greater calls for accountability towards students with disabilities. In recent decades, the focus in special education has shifted from access to accountability. State and federal laws have held educators accountable for demonstrating the progress of students with disabilities working within the general education curriculum. General education teachers are increasingly responsible for the progress of students with disabilities in their classrooms.

Inclusion, which is a philosophy based on acceptance and belonging to a community, was intended to ensure that general education classrooms were structured so that all students could learn and succeed (U.S. Department of Education, 1998). Inclusion is based on an underlying concept of social justice (Obiakor, 2011). As federal laws regarding the education of students with disabilities have evolved, inclusion has occurred with more frequency.

The Education for All Handicapped Children Act (PL 94-142), passed in 1975, gave students with disabilities access to a free and appropriate public education. The concept of the least restrictive environment, a tenet of this law, meant that students were 
to be educated with their general education peers to the greatest extent possible. This was the first stepping stone towards inclusion.

In 2001, the reauthorization of the federal Elementary and Secondary Education Act passed and became known as No Child Left Behind (NCLB). NCLB required states to assess all students in reading and math in grades three through eight. According to Thurlow et al. (2005), the law also mandated states to disaggregate and report assessment scores for students with limited English proficiency, students with disabilities, and minority students. States were to provide reasonable accommodations so that all students could access the assessments. The performance of students with disabilities as a subgroup on these high-stakes tests affected a school's ability to make adequate yearly progress, another provision of NCLB. Again, NCLB was an additional impetus for the move to a more inclusive model for educating students with disabilities.

The 2004 reauthorization of IDEA also emphasized access to the general education curriculum for students with disabilities, including participation in large-scale state assessments. This aligned closely with the provisions of NCLB (Bouck, 2009). Increasingly, students with disabilities were to have access to the general education curriculum, in a classroom with a highly qualified teacher who used research-based instructional strategies. Additionally, these students were to demonstrate proficient levels of achievement in reading and math on statewide assessments aligned to grade level curriculum. Again, providing increased access to the general education curriculum supported a move to more inclusionary practices for students with disabilities.

Since the reauthorizations of the Individuals with Disabilities in Education Act (IDEA) in 1997 and 2004, students with disabilities have spent a greater portion of their 
time in general education classrooms. With the passing of No Child Left Behind (NCLB) in 2001, students with disabilities have also been required to take the same high-stakes tests as their typically developing peers to ensure their progress within and their mastery of the general education curriculum. These legislative mandates have led to an increase in inclusion of students with disabilities for a greater portion of the instructional day (U.S. Department of Education, 2010).

According to Albrecht and Joles (2003), increased accountability requirements have meant that schools had to focus their efforts on all students, including those with disabilities, since assessment results for all students would be reported when measuring yearly school progress and success. These accountability measures have, at their heart, the belief that holding schools responsible for ensuring that all students meet proficiency standards leads to improved educational outcomes for all students, including those with disabilities.

However, research that examines the relationship between inclusion of students with disabilities in the general education classroom and their academic achievement has yielded conflicting results. In general, research in this area has been problematic for a number of reasons. According to Zigmund (2003), although research to determine the best instructional setting for students with disabilities spans thirty years, there are relatively few studies that are methodologically sound and that provide conclusive results. Frequently, these challenges revolve around the difficulty in defining service delivery models or settings, assigning subjects to random treatment groups, and describing treatments thoroughly enough to replicate. In their synthesis of research on inclusion of students with disabilities in early childhood education, Odum, Buyesse and, 
Soukakou (2011) identified factors such as different definitions and forms of inclusion as possible reasons that there is not more research on the outcomes of inclusion. Inclusion can look very different from district to district or even from one school to another. Additionally, much of the research in this area was done in the 1980s and 1990s. Research that examines the academic and social outcomes of inclusion for students with learning disabilities is largely missing or contradictory (Klingner, Vaughn, Hughes, Schumm, \& Elbaum, 1998). Because of this lack of empirical evidence, there is still disagreement about the merits of inclusion for students with disabilities (Rea, McLaughlin, \& Walther-Thomas, 2002).

Despite the lack of clear evidence that inclusion positively impacts student achievement, accountability requirements have made inclusion a reality in most school districts. Research that examines the specific outcomes of inclusion for students with disabilities is not extensive.

In one study that used both qualitative and quantitative data, Idol (2006) examined and described differences and similarities between eight schools, four elementary and four secondary, in how these schools delivered special education services. All schools in this study made efforts to include students with disabilities for portions of the instructional day. Over a four year period, average student test scores on the state performance tests increased. However, this study did not specifically examine the scores for students with disabilities in a disaggregated manner.

Klingner et al. (1998) studied different outcomes for students with and without learning disabilities in inclusive classrooms. Some students with learning disabilities in this study made statistically significant progress in reading based on individually 
administered tests of achievement, although many did not. Students with severe reading disabilities were those who did not make reading progress in the inclusion classroom even when they had special education support. For these students, a combination of services, in which they receive in-class support along with intensive reading remediation through one-on-one instruction, appears necessary.

Rea et al. (2002) compared different outcomes for students with learning disabilities in inclusive and pull-out programs at the middle school level. The inclusive classrooms in this study used one of the co-teaching models previously noted. The authors of this study found that students with learning disabilities in the inclusive setting earned higher course grades in math, English, social studies and science. Additionally, they achieved higher scores on the Iowa Test of Basic Skills on the reading comprehension, science and social studies subtests. However, on state proficiency tests in reading, math, and writing, there was not a significant difference between the performance of students in the inclusive and those in the pull-out group. Finally, there was significant difference in school attendance for those students in the inclusive setting when compared to their peers in the pull-out setting. Students with learning disabilities in the inclusive setting missed less school. So, this study noted positive outcomes for students with disabilities in the inclusive setting in course grades, performance on the Iowa Tests of Basic Skills, and attendance.

In a review of the research on inclusion, Moore, Gilbreath, and Maiuri (U.S. Department of Education, 1998) note that students with disabilities show no differences in reading achievement based on placement in pull-out special education or inclusion settings. However, inclusionary settings did lead to positive experiences and improved 
attitudes towards school for students with disabilities. Odum et al. (2011) also found common themes in the research that indicated that factors such as teacher attitudes, level of collaboration, and amount of ongoing professional development can affect the educational outcomes of inclusion.

In a policy brief about the impact of NCLB on students with disabilities, Cole (2006) asserts that students with disabilities have made progress on state assessments despite the fact that many schools have not made the required adequate yearly progress as defined by the law. In a review of the literature, the author identifies educational, social, and economic benefits of including student with disabilities in the general education classroom. These benefits for students with disabilities include the following:

- Improved academic achievement

- Improved behavior, including higher engagement and lower disciplinary referrals

- Improved high school graduation and college attendance rates

- Increased network of friends

- Improved social skills

- Improved self-esteem and tolerance

- Better post-secondary outcomes

Some research has shown that the amount of time spent in the general education classroom improves the academic achievement of students with disabilities. This is particularly the case if instructional practices that have been shown to be effective with students with disabilities, such as universal design for learning and peer modeling, are used in the general education classroom (Cosier, Cauton-Theoharis, Theoharis, 2013). 
There have not been longitudinal studies that compare the academic achievement of students with disabilities in inclusion settings to those in special education classrooms. Often, the positive impacts of inclusion indicated in the research, for both students with disabilities and their typically developing peers, have more to do with social emotional gains, such as friendships, self-esteem, and social relationships (Meyer, 2001). Although some research does indicate that inclusion positively affects academic achievement, there are also other factors such as reading ability, which impacted overall achievement for students with special needs in inclusive classrooms (Lamport, Graves, \& Ward, 2012).

The research on inclusion of students with disabilities in the general education classroom and their subsequent academic achievement has been inconclusive. Although students with disabilities are spending more of their time in the general education classroom, they lag behind their peers on state tests in math and reading. As noted previously, this gap in state test scores can be as much as 30-40\% for students with disabilities (Cole, 2006). During this age of accountability for the progress of all students, determining ways that the academic achievement of students with disabilities can be improved is essential (Wentzel \& Wigfield, 1998). Teacher efficacy is one pathway to positively affect academic achievement.

\section{Conceptual Framework of Teacher Efficacy}

The research on teacher efficacy follows two main strands, one based on Rotter's social learning theory and the other on Bandura's social cognitive theory. Together, Rotter's work and Bandura's work form the theoretical framework underlying the concept of teacher efficacy. 
Rotter's social learning theory (1966) established a new aspect of personality.

He identified the concept of locus of control which refers to an individual's perception about the level of control they have over events in their life. In other words, do things happen in life as a result of a person's actions or by random chance? Those who believed that events were not based on their own behavior, but due instead to luck, fate or some other outside force, were said to have an external locus of control. A belief in an external locus of control leads to passivity and to a worldview that one is unable to control one's own destiny. Conversely, if a person believed that an event was due to his own effort or characteristics, then they had an internal locus of control. Those with an internal locus of control demonstrated a desire and striving for achievement since they possessed a world view that what they had control over what happened in their life.

In 1976, Rotter's work was the impetus for including additional items on a RAND questionnaire that examined various reading programs and interventions. This extensive questionnaire, developed by RAND researchers, was designed to measure teacher characteristics and student learning, specifically in the area of reading. Results of the RAND study found that teacher efficacy was related to variability in the reading achievement of minority students (Tschannen-Moran et al., 1998). Based on Rotter's seminal work (1966), these two additional items were added to the RAND questionnaire measuring teacher perceptions of their own capabilities, or teacher efficacy (TschannenMoran \& Woolfolk Hoy, 2001).

RAND item 1: When it comes right down to it, a teacher really can't do much because most of a student's motivation and performance depends on his or her home environment. 
RAND item 2: If I really try hard, I can get through to even the most difficult or unmotivated students. (Tschannen-Moran et al., 1998, p. 204).

These two items returned surprising results, and the concept of teacher efficacy had its beginning. The definition of teacher efficacy is a teacher's belief that she can influence how well students learn, even if they are unmotivated or difficult to teach. The two additional Rand items identified two constructs within the concept of teacher efficacy: general teaching efficacy and personal teaching efficacy.

General teaching efficacy referred to a teacher's beliefs about the power of teachers in general, to influence student outcomes over and above the power of external factors, such as home environment, student cognitive abilities, or socioeconomic level. Personal teaching efficacy referred to a teacher's beliefs about his or her own specific, personal ability to bring about change in her own students (Tschannnen-Moran et al., 1998).

Bandura's social cognitive theory, the other strand of research relating to teacher efficacy, includes the construct of "self-efficacy." Teacher efficacy is considered to be a type of self-efficacy. Bandura (1998) defines self-efficacy this way:

Perceived self-efficacy operates as a central self-regulatory mechanism of human agency. People's beliefs that they can produce desired effects by their actions, influence choices they make, their aspirations, level of effort and perseverance, resilience to adversity and vulnerability to stress and depression (Bandura, 1998, p. 51)

According to Bandura, efficacy beliefs affect motivation and performance. Selfefficacy is a stronger predictor of future performance, and is stronger even than past 
performance (Bandura \& Locke, 2003). Those with low self-efficacy attribute failure to low ability. However, those with high self-efficacy attribute failure to lack of sufficient effort (Bandura, 1998). In addition, those with high self-efficacy have better coping behaviors, set higher goals, and have a stronger commitment to meeting those goals. Efficacy beliefs affect whether a person thinks strategically or erratically, as well as whether they think optimistically or pessimistically (Bandura, 1993; Bandura, 2006).

Eventually, Bandura (1993) identified teacher efficacy as a type of self-efficacy. He theorized that a teacher's belief in her ability to motivate her students and to facilitate student learning has an effect on the type of learning environment she is able to create and on the academic progress of her students. According to Gibson \& Dembo (1984):

If we apply Bandura's theory to the construct of teacher efficacy, outcome expectancy would essentially reflect the degree to which teachers believed that environment could be controlled, that is, the extent to which students can be taught given such factors as family background, IQ, and school conditions. Self-efficacy beliefs would be teachers' evaluation of their abilities to bring about positive change ( $\mathrm{p}$. $570)$.

Teaching efficacy is a self-perception. It is not an objective measure of a teacher's actual abilities or competence (Ross \& Bruce, 2007; Tshannen-Moran et al., 1998). This self-assessment of teaching efficacy relies on judgments in two related domains. The first has to do with the requirements of a task. A teacher views her teaching competence in light of the requirements of a specific task. Consideration of the requirements of the task includes the following: resources available; student factors such 
as ability, motivation, and socioeconomic status, and; school factors such as leadership and support of colleagues (Tshcannen-Moran et al., 1998; Tshcannen-Moran \& Woolfolk Hoy, 2006).

Additionally, self-assessment of teaching efficacy is context specific, and relies on teacher judgment of personal strengths and weaknesses in different contexts. For instance, a teacher might feel efficacious when teaching language arts, but not when teaching math or science (Ashton \& Webb, 1986; Tschannen-Moran \& Woolfolk Hoy, 2006).

\section{Instructional Practices Associated with Teacher Efficacy}

Teacher efficacy impacts teacher behaviors such as instructional method choices, effort, and persistence (Putnam, 2012). These teacher behaviors are related to student achievement (Ashton \& Webb, 1986).

In their seminal qualitative study on teacher efficacy, Ashton and Webb (1986) established a relationship between a teacher's sense of efficacy and student achievement. Their study was an ethnographic analysis in which they used interviews and participant observations of middle school teachers to gather their data. They determined that efficacy is situational and can be related to the subject matter being taught, and that higher efficacy leads to a warmer classroom climate, characterized by harmony and relationships that are friendly. In addition, they found that when teachers have higher efficacy beliefs, their students' efficacy is higher, and students believe more in their own ability to succeed academically.

Ashton and Webb (1986) clearly delineated differences in teacher behaviors between those with high and low efficacy in regards to building student relationships. 
Teachers with high efficacy build warm relationships with their students, making fewer negative comments and using fewer instances of removing students from the classroom for misbehavior. They believe all students can learn, and they exert personal authority by virtue of respect. Low efficacy teachers, on the other hand, make classroom discipline a priority and classroom situations are defined in terms of conflict. The teacher's position is the basis for authority, rather than a relationship of mutual respect.

Additionally, Ashton and Webb (1986) identified differences in classroom management strategies between teachers with high and low efficacy. Teachers with high efficacy had classrooms that were relatively harmonious. They were less likely to construe rule infractions by students as challenges to their authority. Teachers with low efficacy were more likely to publicly embarrass students and to make students leave the classroom when they broke a rule. Dembo and Gibson (1985) also found that teachers with low efficacy are more likely to use harsh control tactics.

Finally, Ashton and Webb (1986) found differences in instructional strategies between high and low efficacy teachers. Teachers with high efficacy were more likely to walk around the room while students were working independently, answering questions and monitoring student progress. High efficacy teachers displayed a sense of "with-itness," knowing what was going on at all times in the classroom and they were more likely to praise students frequently (Ashton \& Webb, 1986; Dibapile, 2012). Teachers with low efficacy were more concerned with containment and control, rather than teaching and learning. Ashton and Webb (1986) also found that teachers with low efficacy made less effort with low achieving and struggling students. 
In the classrooms of teachers with high efficacy beliefs, ability is an acquirable skill. Learning occurs from mistakes and students are encouraged to seek out challenges in order to extend their knowledge. The level of effort determines failures and successes. This constitutes a positive learning environment that promotes student academic achievement. For those with low efficacy, ability often corresponds to intellectual capabilities, and efficacy plummets in the face of problems or challenges. They tend to believe that low ability is the cause of failure (Bandura, 1993; Dweck, 2006).

In general, teachers with high efficacy create strong, positive learning environments that reduce the number of struggling students. They use teaching approaches like modeling, coaching, and fading support, all of which have been shown to relate to student learning and higher achievement. In addition, high efficacy teachers are more likely to use group alerting techniques and accountability to convey clear expectations for behavior and for high quality of student work (Dibapile, 2012).

However, it is important to remember that the relationship between efficacy and student achievement is correlational, not causal (Dembo \& Gibson, 1985). Teacher efficacy correlates to certain behaviors and these, in turn, correlate to student achievement. Teacher efficacy is one variable of many that account for the variability in teacher effectiveness. Efficacy impacts teacher behaviors such as use of direct instruction, deeper coverage of content, provision of structured academic activities that are teacher supervised, monitoring of student progress, and use of specific questioning strategies including immediate feedback (Gibson \& Dembo, 1984). All of these teacher behaviors reflect instructional practices that have been associated with improved student achievement (Goddard, Hoy, \& Woolfolk Hoy, 2004). 


\section{Instructional Practices Associated with Student Achievement}

The instructional practices that are associated with higher teacher efficacy are also related to higher academic achievement. This is because research shows that these instructional practices lead to higher student engagement and motivation (Whitley, 2010). Forming personal relationships with students, giving them choices in the classroom, and persevering with struggling students are all characteristics of teachers with high efficacy. These same teacher behaviors are also associated with higher student achievement (Wentzel \& Wigfield, 1998).

Instructional practices that are specifically related to the achievement of students with learning disabilities include small-group instruction, instruction of clearly defined skills, providing an appropriate pace of instruction including time for student mastery, opportunity for independent practice and progress monitoring (McLeskey \& Waldron, 2011). Many of these instructional practices are associated with teachers who have higher efficacy.

Additionally, teachers with low efficacy have weak commitment to their goals. They focus on a student's weaknesses, not their strengths, and they attribute failure to low ability. They are more prone to stress and depression. They are also slower to recover self-efficacy after having experienced failure (Bandura, 1998).

Teacher beliefs, about both personal teaching efficacy and general teaching efficacy, have a positive impact on behaviors that contribute to teaching effectiveness and student achievement. The research shows that higher teacher efficacy leads to improved instructional practice, classroom management skills, and positive relationships with students (Ashton \& Webb, 1986). The quality and characteristics of teachers' 
instructional practice do positively affect student achievement (Ashton \& Webb, 1986;

Dibapile, 2012; Tschannen-Moran et al., 1998).

\section{General Education Teachers' Efficacy and Inclusion}

Given the positive teacher behaviors associated with higher efficacy that correlate to student achievement, the fact that $65 \%$ of general education teachers report that they favor inclusion of students with disabilities, but only $29.2 \%$ say they have adequate training and expertise to meet the needs of these students in their classrooms indicates that there might be a tendency towards lower efficacy of general education teachers concerning the students with disabilities in their classrooms (Scruggs \& Mastropieri, 1996). The variance in teacher perceptions regarding inclusion of students with disabilities is due to two variables, which include understanding of inclusion and perceived ability to get through to difficult or unmotivated students.

General education teachers report that they need professional development in the areas of program modification, assessing academic progress, adapting curriculum, managing behavior, developing IEPs, and using assistive technology to meet the needs of the students with disabilities in their classrooms. Overall, $78 \%$ of general education teachers report needing, but not having, adequate in-service training to work with students with disabilities (Buell et al., 1999). General education teachers have lower efficacy for inclusion than special education teachers do (Coladarci \& Breton, 1997; Shippen et al., 2011). Consequently, general education teachers report being frustrated with inclusion, which negatively affects the quality of instructional practice in classrooms that include students with disabilities (Kilanowski-Press et al., 2010). 
According to Chu (2011), general education teachers with lower efficacy demonstrated certain behaviors that included: (a) they were more likely to give up and refer a student who was struggling academically for special education services; (b) they were more likely to refer students for special education services based on factors like lack of student effort, and lack of parental support, and; (c) they did not consider lack of teacher effort or the strategies of a school system in their decision to refer to special education.

On the other hand, general education teachers with higher efficacy were more likely to try different strategies with struggling students, even those students from culturally and linguistically diverse backgrounds (Chu, 2011). According to Coladarci and Breton (1997) general education teachers with higher efficacy were more likely, as well, to prefer collaborative work relationships, such as those found in co-teaching relationships with a special education teacher. Gotshall and Stefanou, (2011) reported that higher efficacy general education teachers have lower levels of anxiety towards inclusion of students with disabilities and an overall more positive view of inclusion. Teachers with lower self-efficacy, on the other hand, prefer to refer students to special education rather than attempt classroom interventions, and their students are more likely to develop a sense of learned helplessness. Additionally, teachers who have high teaching efficacy will work with a struggling student for a longer period of time even when they are failing (Ashton \& Webb, 1986; Soodak et al.,1998; Tschannen-Moran et al., 1998). All of these factors contribute to the successful academic progress and achievement of students with disabilities in the general education classroom. 
In Soodak and Podell's (1993) study, both special education and general education teachers took the Teacher Efficacy Scale (Gibson \& Dembo, 1984), a measure of teaching efficacy, and responded to case studies. Findings of this study indicated that the higher a general education teacher's efficacy was, the more likely they were to believe that diverse students belonged in their class and the more receptive they were to the inclusion of students with disabilities in their classrooms. Additionally, a teacher's willingness to include students with disabilities in their classroom varied with the nature and severity of the disability. Teachers were less likely to feel comfortable including students with more severe cognitive and physical disabilities in the general education classroom.

Expanding on this research, Soodak et al. (1998) surveyed general education teachers about including students with disabilities in their classroom and correlated these results with scores on the Teacher Efficacy Scale (Gibson \& Dembo, 1984). They reported that, in general, teachers were more favorable to having students with high incidence disabilities, like learning disabilities or attention deficit hyperactivity disorder, than they are to having students with severe disabilities, including cognitive, physical, or emotional disabilities in inclusive classrooms. In this study, teachers were more resistant to inclusion of students with behavioral disorders and emotional disabilities. Overall, anxiety towards working with students with disabilities correlated to lower personal teaching efficacy. Class size also impacted teacher anxiety about inclusion. The bigger the general education class size, the higher the anxiety was of the general education teacher about having students with disabilities in her class. 
Personal teaching efficacy correlates with levels of anxiety about working with students with disabilities. A high level of resistance on the part of general education teachers towards inclusion of students with behavioral and cognitive disabilities indicates the need for training in strategies for working with these students (Soodak et al., 1998). Although inclusion of students with disabilities in the general education classroom has been legally mandated and is happening on the front lines, more needs to be done to ensure that general education teachers feel prepared to meet these students' educational needs (Smith \& Tyler, 2011). Some research hypothesizes that this lack of training regarding teaching students with special needs may be because many general education teachers entered the profession before the implementation of inclusion began in the 1990s (Grskovic \&Trzcinka, 2011).

Overall, $78 \%$ of general education teachers report needing but not having adequate inservice training and coursework to work with students with disabilities (Buell, et al., 1999; deBettencourt, 1999; Grskovic \& Trzcinka, 2011; Kosko \& Wilkins, 2009; Smith \& Tyler, 2011). In one study, nearly $40 \%$ of general education teachers reported that they had taken no coursework at all that dealt with teaching students with special needs (deBettencourt, 1999). Determining what variables contribute to general education teachers' efficacy concerning students with disabilities could affect the academic achievement of these students.

\section{Measurement of Teacher Efficacy}

As previously noted, Gibson and Dembo (1984) developed a measure of teacher efficacy called the Teacher Efficacy Scale. Originally, the Teacher Efficacy Scale contained 30 items. Factor analysis indicated that 16 of those items correlated directly with two factors. Factor 1 was personal teaching efficacy, which accounted for $18.2 \%$ of 
total variance. Factor 2, which correlated with general teaching efficacy, accounted for $10.6 \%$ of total variance. Each of the remaining factors identified explained about $6 \%$ of total variance. The sum of the general teaching efficacy and personal teaching efficacy items was the overall teacher efficacy score.

The Teacher Efficacy Scale is a widely used measure of teacher efficacy. Studies of both experienced and pre-service teachers indicate that both personal teaching efficacy and general teaching efficacy explain between $18 \%$ and $30 \%$ of the variance between teachers (Tshannen-Moran \& Woolfolk-Hoy, 2001). Using the Teacher Efficacy Scale measure, teacher efficacy scores correlate to a teacher's willingness to implement new things, stress level, and his or her willingness to stay in the field of education (Tschannnen-Moran et al, 1998).

Similar to the findings of Ashton and Webb (1986), correlates to high scores on the Teacher Efficacy Scale include teacher behaviors such as being less likely to criticize students when they answer incorrectly, more likely to persevere with a student when they are struggling, more likely to divide the class for small group instruction rather than provide solely whole group instruction, and increased willingness to work with difficult students. Some of the student outcomes of higher teacher efficacy scores were greater student interest in school, and increased student perception that what they are learning was important. Higher teacher efficacy, again, correlated to improved student achievement (Tshannen-Moran et al., 1998).

\section{Similar Theories}

In the literature, the concept of teacher efficacy has been repeatedly associated with teacher behaviors that correlate to student achievement. Similar theories that 
examine sense of agency, or self-efficacy, and locus of control have been identified more recently. These newer theories relate to the conceptual frameworks proposed by Rotter's social learning theory (1966) and Bandura's social cognitive theory (1977).

Dweck's (2006) current research elaborates on Bandura's and Rotter's theories in terms of motivation and attribution of causes of failure. She identifies those with a "growth mindset" as believing that intelligence and talent are not fixed traits but can be achieved or changed through hard work and perseverance in the face of challenges and obstacles. Those with a growth mindset are more likely to see effort as the path to improvement and mastery. They do not give up in the face of failures and believe they can learn from their mistakes. Dweck's description of a growth mindset closely aligns with high efficacy. According to Dweck, a teacher with a growth mindset is more likely to praise the effort of her students, not their abilities, which leads to developing motivation and a growth mindset in her students.

Similarly, Dweck (2006) describes those with the opposite mindset, a "fixed mindset," which closely approximates characteristics of those with low efficacy. Those with a fixed mindset, Dweck says, believe that talent, ability and intelligence are all fixed traits. They avoid hard work and effort because the need for these things means that you are not capable or intelligent. Those with a fixed mindset want to appear smart at all costs and therefore give up easily and avoid challenges for fear that failure will affirm their lack of ability or intelligence.

Additional new research on the construct of "grit" mirrors findings about efficacy. Duckworth et al. (2007) define grit as "perseverance and passion in pursuing long-term goals". Although this research does not explore the connection between self-efficacy and 
grit, the characteristic of pursuing and persevering with long term goals, despite failure and setbacks, is common to both. Both Dweck's (2006) research on "mindset" and Duckworth et al.'s (2007) research on "grit" give current and continuing validity to the concept of self-efficacy, although it is called by another name. As previously noted, selfefficacy, as defined by Bandura (1977), is the basis for the concept of teacher efficacy.

\section{Teacher Efficacy Antecedents}

Experiences as sources of teaching efficacy. As previously discussed, the notion of teacher efficacy evolved from the initial conceptions of self-efficacy (Bandura, 1997). Bandura (1998) identified four sources of self-efficacy. These are mastery/enactive experiences, vicarious experiences, social/verbal persuasion, and physiological arousal, also referred to as affective state experiences. According to Bandura, mastery experiences have the most impact on efficacy and changes in efficacy, in turn, change behaviors. Changes in behaviors that follow mastery experiences are the most enduring and generalizable (Bandura, 1998; Labone, 2004).

Mastery experiences refer to those that lead to content mastery or pedagogical mastery. Bandura (1977) indicates that mastery experiences, also referred to as performance accomplishments, include participant modeling and self-instructed performance. When a teacher experiences success with a student, or with a lesson, she has a mastery experience. Mastery experiences are "enactive" in that the teacher establishes change or impact through her own behaviors (Bautista, 2011). According to Bandura (2006), powerful mastery experiences can be transformative in changing a teacher's efficacy beliefs. Tschannen-Moran and colleagues (1998) note that these experiences can form part of a cycle: higher teacher efficacy leads to higher teacher effort 
and persistence, which results in better student outcomes and new mastery experiences, which in turn further increases teacher efficacy.

Vicarious experiences are those in which one teacher observes another experiencing success. Observation and modeling are two examples of vicarious experiences. Bautista (2011) examined the effects of vicarious and mastery experiences on pre-service teachers' efficacy beliefs. The pre-service teachers in this study observed another teacher teach (effective actual modeling), watched a video of another teacher teaching (symbolic modeling), watched a video of herself teaching and reflected on her performance (self-modeling), and imagined themselves performing an instructional strategy successfully (cognitive self-modeling). Bautista (2011) found that mastery and vicarious experiences were the most powerful in changing pre-service teachers' efficacy. Additionally, vicarious experiences are thought to influence teaching efficacy beliefs in the case of new teachers who have limited prior experiences on which to base their teaching efficacy perceptions (Labone, 2004). Vicarious experiences are more powerful when the observer identifies with the person who is doing the modeling (TschannenMoran \& Woolfolk Hoy, 2006).

Social persuasion experiences are those in which a teacher receives feedback or affirmation from a supervisor, peer, or cooperating teacher. Bandura (1977) includes suggestion and self-instruction among social persuasion experiences. The interpersonal support that teachers receive from administrators, colleagues, parents, or the school community is considered a type of social persuasion experiences (Tschannen-Moran \& Woolfolk Hoy, 2006). Social persuasion also includes coursework and professional development experiences (Tschannen-Moran et al., 1998). Additionally, social persuasion 
experiences are only effective in changing teaching efficacy when the person giving the feedback is perceived to have expertise, trustworthiness, and credibility by the person who receives it (Bandura, 1977).

Finally, affective state experiences refer to the level of stress, anxiety, or excitement that a teacher experiences and his or her response to that stress or excitement. Bandura (1977) included experiences that involve biofeedback and relaxation strategies in this category as ways to affect one's affective state. Higher levels of stress can decrease a teacher's efficacy. According to Putnam (2012), who added to Bandura's definition, affective state experiences include physical symptoms of the body, including sweating and increased heart rate. When these physical symptoms occur, they can cause a teacher to doubt his or her abilities, thereby decreasing efficacy for that task and in that particular situation.

Although all four types of experiences theoretically impact efficacy, the most powerful way of building efficacy, according to Bandura (1998) is through mastery experiences. These mastery experiences can be transformative and produce stronger and more generalizable efficacy beliefs (Bandura, 1977; Bandura, 2006). Other research identifies both mastery experiences and vicarious experiences as the having the strongest impact on efficacy (Bautista, 2011; Buss, 2010; Putnam, 2012).

The literature points to the malleability of efficacy. Researchers have examined two variables that give support to the belief that change in teaching efficacy can occur. The first variable examined in the literature is content areas in which teaching efficacy can change. Mastery experiences for pre-service teachers with low efficacy in science and math had a positive impact in a study conducted on 325 undergraduate students 
(Buss, 2010). Buss (2010) suggests providing live and virtual observation opportunities, including videos and internet-based materials, for elementary teachers with low efficacy in content areas to increase their efficacy for the content areas of math and science.

The second variable examined in the literature is when, in the trajectory of a teaching career, teaching efficacy is most malleable. Bandura postulated that efficacy is most changeable early in the learning process, which is why so much of the effort towards improving efficacy has been directed towards pre-service programs. In research conducted by Forlin, Earle, and Sharma (2011), researchers designed a scale to measure pre-service teachers' sentiments, attitudes and concerns about inclusion. They found that higher efficacy of pre-service teachers predicted success in their later instructional practice. Historically, the biggest fear of pre-service teachers preparing to enter the teaching profession expressed in interviews with researchers was working with students with special needs, specifically severe disabilities (McLeskey, Henry, \& Hodges, 1999).

Yellin and colleagues (2003) conducted an evaluation of the impact of an inclusionary practicum experience on attitudes of 55 pre-service teachers towards students with disabilities. They found that mere exposure to students with disabilities is necessary but not sufficient enough to significantly change the beliefs and anxieties of pre-service teachers. In their comprehensive overview of the current state of teacher efficacy research and measurement of the era, Tschannen- Moran et al. (1998) suggested that adding additional coursework in special education instruction and experiences with students with disabilities at the undergraduate level appeared necessary.

Gao and Mager (2011) studied the effects of an inclusive teacher education program in the United States in which special education content was infused into the 
entire teacher preparation program. They found that pre-service teachers trained in such a program had more positive attitudes about including students with social and academic weaknesses in the general education classroom. Additionally, they had more positive attitudes about diversity in their classrooms, in general, indicating that intentional changes to pre-service programs can positively impact general education teacher efficacy towards students with disabilities and towards inclusionary practices

Conflicting results in the research are evident regarding the impact years of experience has on efficacy. Dembo and Gibson (1985) reported that beginning teachers had higher efficacy than student teachers, and that efficacy continued to rise with 5 to 10 years of experience, but then began to decrease with more years in the teaching profession. However, Tschannen-Moran et al. (1998) reported that efficacy remains stable for in-service teachers and that any changes in efficacy are difficult to maintain. Other research (Putman, 2012)) reports that efficacy drops during the first year of teaching when new teachers face the day-to-day realities of the profession. Contradicting this research, Coladarci and Breton (1997) report that older, more experienced teachers have a slightly higher sense of teaching efficacy. It does appear years of experience affects teaching efficacy, although it is not clear in which direction at different points in a teacher's career.

Professional development as source of teaching efficacy. There is evidence that the efficacy of experienced teachers can be changed, as well. Professional development is one possible pathway to changing teaching efficacy for in-service teachers.

The amount of professional development a general education teacher participates in is statistically significant and positively related to her perceived ability to adapt 
instruction for students with special needs (Kosko \& Wilkins, 2009). One common characteristic of high efficacy teachers is the number of courses they have taken. Efficacy increases when teachers receive training in content and in instructional strategies that are successful with diverse learners (Swackhamer, Koellner, Basile, \& Kinbrough, 2009).

Joyce and Showers (2002) found that professional development which involves practice of a skill has better transfer to the classroom. Practice with a specific skill is more effective in impacting teaching efficacy than simply studying theory or watching someone else demonstrate a skill. The researchers determined that the highest degree of transfer and strength of skill development occurred during peer coaching. Peer coaching involves teachers observing and learning from one another. According to Joyce and Showers (2002), feedback and judgment are not components of peer coaching. Learning and implementation of new curriculum and instructional practice is the goal of coaching, not evaluation.

In their comprehensive look at professional development and its link to student achievement, Joyce and Showers (2002) examined case studies in which professional development that included coaching contributed to greater transfer of skills. In their work, coaching provided many benefits. First, coached teachers practiced new instructional skills more often, and they used these skills more appropriately and with greater fidelity. They also had greater long term retention of the strategies and were more likely to explain new teaching methods to students. Finally, they had a clearer understanding of the newly learned instructional strategy in terms of its purposes and 
uses. Thinking and reflecting on the effects of teacher behaviors on student learning is an important component of peer coaching (Joyce \& Showers, 2002).

In their comprehensive review of the research on teacher efficacy at the time, Tschannen-Moran and colleagues (1998) found that teachers with high efficacy were more likely to be willing to work with a coach. Joyce and Showers (2002) found that working with a coach correlated to increased student achievement.

In addition to coaching, professional development that directly addresses teachers' knowledge base and instructional skills positively impacts teaching efficacy. In a quasi-experimental study, Huai, Braden, White, and Elliott ( 2006) studied the effects of a multi-media internet based pre and post measurements on skill levels and selfefficacy for a treatment group (received the internet based professional development) and a control group. The results of this study found web-based professional development instruction to be effective in improving participants' knowledge of assessment practices and self-efficacy in both general education and inclusive settings. There appears to be a high correlation between knowledge and self-efficacy. When one improves, the other improves in response. The authors of this study concluded that web-based instruction can increase a teacher's knowledge base and thereby his or her teaching efficacy

Ross and Bruce (2007) also studied the results of professional development on teacher efficacy. Using a randomized field trial on all elementary schools in one Canadian district, sixth grade math teachers took an efficacy measurement scale before and after a day of professional development on teaching standards-based math. Ross and Bruce (2007) found that quality professional development increases the instructional skills of the teacher and that this might directly contribute to higher efficacy. In this 
study, the results were statistically significant for changes in efficacy regarding classroom management skills. The researchers suggest that increased confidence in keeping students engaged and using new instructional strategies learned as a result of the professional development experience helped improve the teachers' perceptions of their own classroom management skills on the efficacy scale. When professional development experiences target known sources of efficacy, then teacher efficacy and confidence increase.

Darling-Hammond and Richardson (2009) identified some additional professional development opportunities that are job embedded and that can improve a teacher's instructional practice leading to increased student achievement. The first of these professional development opportunities is peer observation of practice, in which teachers observe in one another's classrooms and give each other feedback and assistance. In some cases, teachers videotape themselves teaching for later peer review. According to the researchers, peer observation of practice has helped teachers improve their practice, knowledge, and overall effectiveness.

The second type of professional development opportunity identified by DarlingHammond and Richardson (2009), that is readily available in the school, is analysis of student work and data. In this opportunity, teachers meet with a professional learning community to focus on a common understanding of expectations for student work and to share effective instructional strategies. Sometimes referred to as a data dialogue, because student data is shared and reflected upon, these experiences can also result in higher student achievement according to the researchers. Finally, Darling-Hammond and Richardson (2009) identified study groups as a type of job embedded professional 
development opportunity. Study groups meet to discuss and learn about educational research and instructional practice have shown the ability to transform instructional practice and, thereby, increase student achievement. According to Darling-Hammond and Richardson, (2009) a professional learning community with shared goals can lead to positive professional development that increases teachers' instructional skills which, in turn, positively affects teaching efficacy. 


\section{Chapter 3}

\section{Overview of Methodology}

This chapter describes the methodology used to collect and analyze data in this study, including the following: statement of the purpose of the study and the research questions; explanation of the study design; description of the selection of the population and study sample; justification for the instrumentation; and description of the method for data collection and data analysis.

\section{Purpose and Research Questions}

The purpose of this study was to determine if the frequency with which general education teachers have had experiences identified by Bandura as efficacy sources is related to differences in their teaching efficacy concerning students with disabilities. In effect, this study tested Bandura's theory, which suggests that certain experiences (mastery, vicarious, social persuasion, and affective state) contribute to higher levels of efficacy, specifically in the case of general education teachers concerning students with disabilities. Although data was collected on the frequency of all four types of experiences, only the data for mastery, vicarious, and social persuasion experiences was analyzed because the literature supported these types of experiences as having the strongest effect on teaching efficacy (Bandura, 1998; Bandura, 2006; Bautista, 2011; Ross \& Bruce, 2007). 
In order to achieve the purpose of this study, these questions were considered:

1. Are differences in the frequency of mastery experiences related to differences in personal teaching efficacy?

2. Are differences in the frequency of mastery experiences related to differences in general teaching efficacy?

3. Are differences in the frequency of mastery experiences related to differences in total teaching efficacy?

4. Are differences in the frequency of vicarious experiences related to differences in personal teaching efficacy?

5. Are differences in the frequency of vicarious experiences related to differences in general teaching efficacy?

6. Are differences in the frequency of vicarious experiences related to differences in total teaching efficacy?

7. Are differences in the frequency of social persuasion experiences related to differences in personal teaching efficacy?

8. Are differences in the frequency of social persuasion experiences related to differences in general teaching efficacy?

9. Are differences in the frequency of social persuasion experiences related to differences in total teaching efficacy?

\section{Design}

The design of this study was both descriptive and correlational. Survey methodology was employed to gather the data needed for analysis. The unit of analysis was the individual teacher. 
Survey methodology was best to determine if the frequency of mastery, vicarious, and social persuasion experiences relates to different levels of general education teacher efficacy towards students with disabilities. Using survey methodology allowed access to more teachers in the sample group since the survey was emailed, and allowed the researcher to obtain the needed information from respondents with a minimum of time required from each participant. Respondents answered the questions using brief responses to structured questions. Respondents needed 10 to 15 minutes to complete the 20-question survey, which increased the chances of a reasonable response rate.

The independent variable in this study was the extent to which teachers have participated in certain experiences - mastery, vicarious, and social persuasion experiences — identified by Bandura (1977) as sources of teaching efficacy. The dependent variable was the teaching efficacy beliefs of general education teachers concerning students with disabilities. The variable of years of experience teaching students with disabilities was statistically analyzed to determine if it was positively correlated to the frequency of mastery, vicarious, and social persuasion experiences. A positive correlation was found for mastery and vicarious experiences, so there was no need to control for this variable when analyzing these results. However, no such correlation was found in the case of social persuasion experiences, so the years of experience variable had to be controlled when analyzing the results for this type of experience.

\section{Participants}

The initial population for this study was all elementary general education teachers in one large suburban school district in Virginia. This district has 139 elementary 
schools. In order to identify a more representative sample, the district required that the elementary schools be divided into four categories based on free and reduced lunch/fees data, and that the sample be drawn equally from each of those four groups. Ten schools were chosen from each of these categories for a total of 40 elementary schools.

Each elementary school has 7 grade levels represented, Kindergarten through sixth grade. An estimate of two classes per grade level would be inclusion classes at each school. If an average of 14 general education teachers (two at each grade level) at each elementary school have students with disabilities in their class, then a reasonable estimate of the total sample of general education teachers with students with disabilities in the chosen schools that were sent the survey is 560. Based on 106 survey respondents, the response rate for the survey was $19 \%$.

Socioeconomic groupings were based on data from the 2011/2012 school year located on the demographic data tab of each elementary school's webpage. Schools were chosen randomly by picking school names from a bag. Four bags were drawn from, each one containing the names of all the schools in the four different socio-economic status quartiles, establishing the 40 schools for this study.

Following district approval of the schools identified for the sample, the researcher contacted principals of each of the selected schools and asked them to forward an email and survey to the general education teachers in their school who had students with disabilities in their classes. District approval of this study stipulated that the survey be sent to principals, not directly to teachers. As a result, the researcher did not know how many teachers actually received the survey. This is a limitation that affected response 
rate and knowledge of the actual sample size (how many teachers actually received the survey).

Principals received the link to the survey, constructed in Survey Monkey, in the initial email sent out. Two follow-up reminders were sent to principals at one-week intervals from the date of the initial email, with the survey link.

\section{Instrumentation}

This study employed a two-part survey to collect information on both the dependent and independent variables. Part one of the survey measured the dependent variable, general education teacher efficacy beliefs concerning students with disabilities. This part of the survey consisted of the 16-item shortened version of the Teacher Efficacy Scale, amended to reflect teachers' sense of efficacy concerning students with disabilities. The survey was amended by adding the words "with disabilities" to all references to students in the survey questions. The shortened version of the Teacher Efficacy Scale (Gibson \& Dembo, 1984) included only the items that have been shown to be related to personal teaching efficacy and general teaching efficacy. This part of the survey yielded three scores, one for personal teaching efficacy, one for general teaching efficacy, and one for total efficacy, which was the sum of the personal teaching efficacy and the general teaching efficacy scores. Respondents were asked to rate the extent to which they agreed with 16 statements using a Likert scale of 1 to 6 , with 1 being strongly disagree and 6 being strongly agree (See Appendix A).

When Gibson and Dembo (1984) analyzed the items on the Teacher Efficacy Scale, nine of the items on the Teacher Efficacy Scale were factor loaded on the measure of personal teaching efficacy and seven items were factor loaded on the measure of 
general teaching efficacy. A total score for the 16 items provided the total efficacy score for each respondent. The analysis of the internal consistency reliability for the Teacher Efficacy Scale measure indicated Cronbach's alpha coefficients of .78 for Personal Teacher Efficacy, .75 for General Teacher Efficacy, and .79 for the total 16 items on the shortened version of the scale. The items loaded on the first factor, personal teaching efficacy, accounted for $18.2 \%$ of the total variance on the measure. The second factor items, general teaching efficacy, accounted for $10.6 \%$ of the total variance in responses. Based on this data, Gibson and Dembo (1984) presented a shortened version of the Teacher Efficacy Scale, which contained only the 16 items that factor loaded on either personal teaching efficacy or general teaching efficacy. This study used the shortened version of the Teacher Efficacy Scale.

The Teacher Efficacy Scale (Gibson \& Dembo, 1984) is a widely used and accepted measurement of the teacher efficacy construct. There is longstanding evidence for its validity in measuring the construct of teacher efficacy. Although other measures of the construct of teacher efficacy exist, and many are more current, this study used the Teacher Efficacy Scale because it yielded not only an overall efficacy score, but also scores for general teaching efficacy and personal teaching efficacy. Additionally, the Teacher Efficacy Scale has been amended in past research to measure efficacy towards students with disabilities to determine the differences in efficacy between elementary and secondary teachers (Shippen, et al., 2011).

The 16 items on the Teacher Efficacy Scale were coded in the following manner when they were entered into the IBM Statistical Package for the Social Sciences (SPSS), version 21 . Negative items were recoded accordingly when the statistical analyses were 
run. Table 1 notes the factor loading for each item, determined by Gibson and Dembo

(1984).

Table 1

Factor Loading and Coding of Teacher Efficacy Scale Survey Items

\begin{tabular}{|c|c|c|c|}
\hline $\begin{array}{l}\text { Item \# } \\
\text { On Study } \\
\text { Survey }\end{array}$ & Item & Factor Loaded & $\begin{array}{l}\text { Negative or } \\
\text { Positive } \\
\text { Coding }\end{array}$ \\
\hline 2 & $\begin{array}{l}\text { When a student with disabilities does } \\
\text { better than usual, many times it is } \\
\text { because I exerted a little extra effort }\end{array}$ & $\begin{array}{l}\text { Personal TE(1) } \\
.49\end{array}$ & + \\
\hline 3 & $\begin{array}{l}\text { The hours in my class have little } \\
\text { influence on student with disabilities } \\
\text { compared to the influence of their } \\
\text { home environment }\end{array}$ & $\begin{array}{l}\text { General TE (2) } \\
.54\end{array}$ & - \\
\hline 4 & $\begin{array}{l}\text { The amount a student with disabilities } \\
\text { can learn is primarily related to family } \\
\text { background }\end{array}$ & $\begin{array}{l}\text { General TE (2) } \\
.54\end{array}$ & - \\
\hline 5 & $\begin{array}{l}\text { If students with disabilities aren't } \\
\text { disciplined at home, they aren't likely } \\
\text { to accept any discipline }\end{array}$ & $\begin{array}{l}\text { General TE (2) } \\
.60\end{array}$ & - \\
\hline 6 & $\begin{array}{l}\text { When a student with a disability is } \\
\text { having difficulty with an assignment, I } \\
\text { am usually able to adjust it to his/her } \\
\text { level. }\end{array}$ & $\begin{array}{l}\text { Personal TE(1) } \\
.46\end{array}$ & + \\
\hline 7 & $\begin{array}{l}\text { When a student with a disability gets a } \\
\text { better grade than usual, it is generally } \\
\text { because I found better ways of } \\
\text { teaching the student }\end{array}$ & $\begin{array}{l}\text { Personal TE(1) } \\
.46\end{array}$ & + \\
\hline 8 & $\begin{array}{l}\text { When I really try, I can get through to } \\
\text { the most difficult students with } \\
\text { disabilities }\end{array}$ & $\begin{array}{l}\text { Personal TE(1) } \\
.53\end{array}$ & + \\
\hline 9 & $\begin{array}{l}\text { A teacher is very limited in what } \\
\text { he/she can achieve because the home } \\
\text { environment of a student with a } \\
\text { disability is a large influence on } \\
\text { his/her achievements }\end{array}$ & $\begin{array}{l}\text { General TE (2) } \\
.65\end{array}$ & - \\
\hline 10 & $\begin{array}{l}\text { When the grades of my students with } \\
\text { disabilities improve, it is usually } \\
\text { because I found more effective } \\
\text { teaching strategies }\end{array}$ & $\begin{array}{l}\text { Personal TE(1) } \\
.55\end{array}$ & + \\
\hline 11 & If a student with a disability masters a & Personal TE(1) & + \\
\hline
\end{tabular}




\begin{tabular}{|c|c|c|c|}
\hline & $\begin{array}{l}\text { new concept quickly, this might be } \\
\text { because I knew the necessary steps in } \\
\text { teaching that concept }\end{array}$ & .61 & \\
\hline 12 & $\begin{array}{l}\text { If parents with do more with their } \\
\text { children with disabilities, I could do } \\
\text { more }\end{array}$ & $\begin{array}{l}\text { General TE (2) } \\
.52\end{array}$ & - \\
\hline 13 & $\begin{array}{l}\text { If a student with disabilities did not } \\
\text { remember information I gave in a } \\
\text { previous lesson, I would know how to } \\
\text { increase his/her retention in the next } \\
\text { lesson }\end{array}$ & $\begin{array}{l}\text { Personal TE(1) } \\
.51\end{array}$ & + \\
\hline 14 & $\begin{array}{l}\text { If a student with a disability in my } \\
\text { class becomes disruptive and noisy, I } \\
\text { feel assured that I know some } \\
\text { techniques to redirect him/her quickly }\end{array}$ & $\begin{array}{l}\text { Personal TE(1) } \\
.49\end{array}$ & + \\
\hline 15 & $\begin{array}{l}\text { The influences of the home } \\
\text { environment on a student with a } \\
\text { disability can be overcome by good } \\
\text { teaching }\end{array}$ & $\begin{array}{l}\text { General TE (2) } \\
-.52\end{array}$ & + \\
\hline 16 & $\begin{array}{l}\text { If one of my students with a disability } \\
\text { couldn't do an assignment, I would be } \\
\text { able to accurately assess whether the } \\
\text { assignment was at the correct level of } \\
\text { difficulty }\end{array}$ & $\begin{array}{l}\text { Personal TE(1) } \\
.48\end{array}$ & + \\
\hline 17 & $\begin{array}{l}\text { Even a teacher with good teaching } \\
\text { abilities may not reach many students } \\
\text { with disabilities }\end{array}$ & $\begin{array}{l}\text { General TE (2) } \\
.45\end{array}$ & - \\
\hline
\end{tabular}

Part two of the survey measured the independent variable, the extent to which teachers have participated in specific experiences based on Bandura's four kinds of experiences thought to impact efficacy. This section contained four questions, one for each of Bandura's categories. Each of these questions included a definition of the type of experience along with specific examples, based on current professional development research. Respondents were asked to rate the frequency with which they had participated in the different types of experiences on a scale of 1 to 4 , with 1 indicating never (no times per year) and four indicating frequently (three to four times per year) (See Appendix B). 
Table 2 identifies the sources used to establish the validity of the questions on the survey measuring the independent variable, the extent to which teachers have engaged in certain experiences based on the specific experiences Bandura (1977) identified as impacting efficacy.

Table 2

Independent Variable- Expert Sources of Validity

\begin{tabular}{|c|c|}
\hline Experiences & Sources of Validity \\
\hline $\begin{array}{l}\text { Mastery/enactive experiences } \\
\text { - Definition } \\
\text { - Examples }\end{array}$ & $\begin{array}{l}\text { - Bandura (1977); Bautista (2011); Tschannen- } \\
\text { Moran et al. (1998); Goodard, Hoy, \& } \\
\text { Woolfolk Hoy (2004) } \\
\text { - Bandura (1977); Bautista (2011) }\end{array}$ \\
\hline $\begin{array}{l}\text { Vicarious Experiences } \\
\text { - Definition } \\
\text { - Examples }\end{array}$ & $\begin{array}{l}\text { - Bandura (1977); Bautista (2011); Tschannen- } \\
\text { Moran et al. (1998); Goodard, Hoy, \& } \\
\text { Woolfolk Hoy (2004) } \\
\text { - Bautista (2011); Ross \& Bruce (2007); Putnam } \\
\text { (2012); Darling-Hammond \& Richardson } \\
\text { (2009) }\end{array}$ \\
\hline $\begin{array}{l}\text { Verbal/Social Persuasion } \\
\text { - Definition } \\
\text { - Examples }\end{array}$ & $\begin{array}{l}\text { Bandura (1977); Bautista (2011); Tschannen- } \\
\text { Moran et al. (1998); Goodard, Hoy \& } \\
\text { Woolfolk Hoy (2004) } \\
\text { Bautista (2011); Joyce \& Showers (2002); } \\
\text { Putnam (2012); Darling-Hammond \& } \\
\text { Richardson (2009) }\end{array}$ \\
\hline $\begin{array}{l}\text { Affective State } \\
\text { - Definition } \\
\text { - Examples }\end{array}$ & $\begin{array}{l}\text { - Bandura (1977); Bautista (2011); Tschannen- } \\
\text { Moran et al. (1998) } \\
\text { - Bandura (1977), Goodard, Hoy \& Woolfolk } \\
\text { Hoy (2004); Bandura (1998) }\end{array}$ \\
\hline
\end{tabular}

Before the researcher sent out the survey, colleagues were asked to preview the survey questions to ensure that they are clear and easy to answer. If the definition of the 
experience or the specific example needed further clarification, the survey items in part two were amended to reflect that feedback.

\section{Data Collection}

The Institutional Review Board for the Social and Behavioral Sciences approved the research protocol on January 6, 2014 (See Appendix D). The researcher sought and received permission from the school division on April 2, 2014 (see Appendix E) to send out the survey to teachers at the elementary schools in the sample between the dates of June 9 and June 23, 2014.

The researcher sent an email on June 9, the first day of the window, explaining the research, documenting district approval, and asking 40 principals from the selected schools to forward the survey link to teachers at their school who had students with disabilities in their classes. The researcher received one email indicating that this principal would not forward the email to her staff members.

The anonymity and confidentiality of all survey participants was guaranteed. The data from the survey was anonymous. The researcher reported no school names, and names of teacher respondents were unknown since principals forwarded the email and survey link directly to staff members. There was no identifying information in the survey data that would link individual survey results to particular teachers.

\section{Data Analysis}

The independent variable in this study was the extent to which general education teachers have participated in specific experiences. The dependent variable was respondents' efficacy beliefs, including a measure of personal teaching efficacy, general teaching efficacy, and total efficacy. 
This study used descriptive statistics to report the mean, standard deviation, and minimum and maximum data. Some research indicates that teachers with more years of experience have higher efficacy (Whitley, 2010). Correlation analyses were run to determine if there was a correlation between the frequency of mastery and vicarious experiences and years of teaching experience with students with disabilities. In both cases, a positive correlation existed, and so that variable was not controlled for.

In order to answer the research questions about mastery and vicarious experiences, a one-way analysis of variance (ANOVA) was employed to determine the relationship between the extent to which teachers have participated in mastery and vicarious experiences and their teaching efficacy beliefs concerning students with disabilities. A statistical significance level of .05 was used because this level provides commonly acceptable statistical significance information for practitioners.

Because social persuasion experiences were not positively correlated with years of experience teaching student with disabilities, the years of experience variable had to be controlled for. In order to answer the research questions about social persuasion experiences, analysis of covariance (ANCOVA) was employed to determine the relationship between the extent to which teachers have participated social persuasion experiences and their teaching efficacy beliefs concerning students with disabilities. A statistical significance level of .05 was used because this level provides commonly acceptable statistical significance information for practitioners.

Both the ANOVA and the ANCOVA statistical analyses were done using the IBM Statistical Package for the Social Sciences (SPSS), version 21. ANOVA was used to compare the means of the three groups based on the independent variable, the 
frequency with which teachers have had mastery or vicarious experiences, to their means on the dependent variable, their efficacy beliefs concerning students with disabilities to determine if there was a statistical difference between group means. ANCOVA was used to control for the variable of years of teaching experience with students with disabilities when comparing the means of the three groups based on the independent variable, the frequency with which teachers have had social persuasion experiences, to their means on the dependent variable, their teaching efficacy beliefs concerning students with disabilities to determine if there was a statistical difference between group means.

A post-hoc comparison was done to protect against a Type 1 error. A Type 1 error occurs when a significant difference between groups is found that does not actually exist. The post-hoc comparison also determined where differences between groups existed if a difference was found. 


\section{Chapter 4}

\section{Presentation and Analysis of the Data}

This chapter reports the data findings of this study and presents the data in the following manner: 1) correlation data for years of experience and frequency of mastery experiences, frequency of vicarious experiences, and frequency of social persuasion experiences, 2) descriptive statistics data for the independent variable- frequency of mastery, vicarious, and social persuasion experiences , 3) descriptive statistics data for the dependent variable- teaching efficacy beliefs of general education teachers concerning students with disabilities, 4) data from the one-way ANOVA on mastery experiences , 5) data from the one-way ANOVA on vicarious experiences, 6) data from the one-way ANOVA on social persuasion experiences and, 6) data from the post hoc tests.

\section{Correlation Data}

The researcher determined correlation data for mastery experiences, vicarious experiences and social persuasion experiences. This was done in order to establish a positive correlation between both types of experiences and years of experience teaching students with disabilities. Tables 3 and 4 show a positive correlation was found for mastery and vicarious types of experiences, meaning that the years of experience variable did not need to be controlled for. However, a positive correlation was not found for social persuasion experiences (Table 5), so years of experience had to be controlled for in that analysis of variance. 
Table 3

Correlation between Mastery Experiences and Years of Experience

Correlation

Pearson Correlation $\quad .333$

Significance (2-tailed) $\quad .002$

$\mathrm{N}$

86

Correlation is significant at the 0.01 level (2-tailed)

Table 4

Correlation between Vicarious Experiences and Years of Experience

\begin{tabular}{lr}
\hline Correlation \\
\hline Pearson Correlation & .234 \\
Significance (2-tailed) & .030 \\
N & 86
\end{tabular}

Correlation is significant at the 0.05 level (2-tailed)

Table 5

Correlation between Social Persuasion Experiences and Years of Experience

\begin{tabular}{lc}
\hline Correlation \\
\hline Pearson Correlation & -.037 \\
Significance (2-tailed) & .783 \\
N & 86
\end{tabular}

Correlation is not significant at the 0.05 level (2-tailed)

Although 116 respondents opened the survey, only 86 participants completed the survey in its entirety.

\section{Descriptive Statistics}

Table 6 reports the mean and standard deviation for the independent variable - the frequency with which survey respondents have participated in mastery, vicarious, or social persuasion experiences. As previously noted in Chapter 3, questions from the 
survey were based on the sources of efficacy that were identified by Bandura (1977).

These questions included a definition of the type of experience along with specific examples, based on current professional development research. Respondents were asked to rate the frequency with which they had participated in the different types of experiences on a scale of 1 to 4, with 1 indicating never (no times per year) and four indicating frequently (three to four times per year).

Table 6

Descriptive Statistics for Independent Variable: Frequency with which Respondents have Participated in Mastery, Vicarious and Social Persuasion Experiences

\begin{tabular}{lccc}
\hline Variable & $\mathrm{N}$ & Mean & $\mathrm{SD}$ \\
\hline Mastery & 86 & 3.1163 & .83199 \\
Vicarious & 86 & 2.6395 & .89328 \\
Social & 86 & 2.3837 & 1.25715 \\
Persuasion & & & \\
\hline
\end{tabular}

Table 7 provides additional descriptive data on the independent variable, or the frequencies of each answer for the question on mastery experience. The researcher used this data to compress the respondents into three groups, based on their answer for the mastery experience question for the one-way ANOVA. Respondents answering 1 or 2 were compressed into one group, Group A. Those answering 3 were put into Group B, and those answering 4 were put into Group C. 
Table 7

Frequencies of Mastery Experiences

\begin{tabular}{lccc}
\hline Answer & N & Percent & Valid Percent \\
\hline 1.00 & 2 & 1.7 & 2.3 \\
2.00 & 23 & 19.8 & 26.7 \\
3.00 & 26 & 22.4 & 30.2 \\
4.00 & 35 & 30.2 & 40.7 \\
\hline Total & 86 & 74.1 & 100.0 \\
Missing & 30 & 25.9 & \\
Total & 116 & 100.0 & \\
\hline
\end{tabular}

Additionally, table 8 illustrates the frequency of answers (1-4) on the vicarious experience question. In order to parallel the analysis of the mastery experiences, the data was compressed into three groups for the one-way ANOVA using vicarious experiences. Those answering 1 or 2 were again compressed into one group, Group A. Those answering 3 were put into Group B, and those answering 4 were put into Group C.

Table 8

Frequencies of Vicarious Experiences

\begin{tabular}{lccc}
\hline Answer & $\mathrm{N}$ & Percent & Valid Percent \\
\hline 1.00 & 9 & 7.8 & 10.5 \\
2.00 & 28 & 24.1 & 32.6 \\
3.00 & 34 & 29.3 & 39.5 \\
4.00 & 15 & 12.9 & 17.4 \\
\hline Total & 86 & 74.1 & 100.0
\end{tabular}


Table 8 (continued)

\begin{tabular}{lccc}
\hline Answer & $\mathrm{N}$ & Percent & Valid Percent \\
\hline Missing & 30 & 25.9 & \\
Total & 116 & 100.0 & \\
\hline
\end{tabular}

Finally, table 9 illustrates the frequency of answers (1-4) on the social persuasion experience question. In order to parallel the analysis of the mastery experiences, the data was compressed into three groups for the ANCOVA using social persuasion experiences. However, based on the frequencies of answers, the compression was done differently for social persuasion experiences. Those answering 1 were put into Group A. Those answering 2 were put into Group B. Those answering 3 or 4 for the social persuasion question were compressed into one group, Group C.

Table 9

Frequencies of Social Persuasion Experiences

\begin{tabular}{lccc}
\hline Answer & $\mathrm{N}$ & Percent & Valid Percent \\
\hline 1.00 & 27 & 23.3 & 31.4 \\
2.00 & 29 & 25.0 & 33.7 \\
3.00 & 23 & 19.8 & 26.7 \\
4.00 & 7 & 6.0 & 8.1 \\
\hline Total & 86 & & 100.0 \\
Missing & 30 & & \\
Total & 116 & & \\
\hline
\end{tabular}


Table 10 reports the number of participants completing the Teacher Efficacy Scale questions on the survey, the minimum, maximum, mean, and standard deviation for the dependent variable - efficacy beliefs of teachers concerning students with disabilities. As noted previously in Chapter 3, the researcher used the shortened version of Teacher Efficacy Scale (Gibson \& Dembo, 1984) amended to address efficacy beliefs concerning students with disabilities to obtain scores for personal teaching efficacy (PTE), general teaching efficacy (GTE), and total efficacy (TE). The score for total efficacy was the sum of the personal teaching efficacy and general teaching efficacy scores. Answers to the questions on this section of the survey used a seven point Likert scale.

Table 10

Descriptive Statistics for Dependent Variable: Efficacy Beliefs Concerning Students with Disabilities

\begin{tabular}{lccccc}
\hline Variable & $\mathrm{N}$ & Minimum & Maximum & Mean & SD \\
\hline PTE & 89 & 28.00 & 53.00 & 41.5281 & 5.70305 \\
GTE & 89 & 11.00 & 39.00 & 27.2247 & 5.55295 \\
TE & 89 & 44.00 & 91.00 & 68.7528 & 9.35205 \\
\hline
\end{tabular}

Although 116 respondents opened the survey, only 89 of the participants completed the section of the survey that used the shortened and amended version of the Teacher Efficacy Scale (Gibson \& Dembo, 1984).

\section{One-way Analysis of Variance (ANOVA) - Mastery Experiences and Efficacy}

A one-way analysis of variance (ANOVA) was run comparing Groups A, B and C. Again, these groups were established based on the mean scores on the answers to the question measuring frequency of mastery experiences and then compared to their mean 
scores on the Teacher Efficacy scale questions on the research survey. Table 11 displays the descriptive results.

Table 11

One-way Analysis of Variance: Frequency of Mastery Experiences and EfficacyDescriptive Statistics

\begin{tabular}{lllllr}
\hline & Group & N & Mean & SD & \multicolumn{1}{l}{ SE } \\
\hline PTE & A & 25 & 38.7600 & 4.78957 & .95791 \\
& B & 26 & 41.3846 & 5.17747 & 1.01538 \\
& C & 35 & 44.0857 & 5.60132 & .94680 \\
& Total & 86 & 41.7209 & 5.64155 & .60834 \\
& & & & & \\
\hline GTE & A & 25 & 26.2800 & 5.42771 & 1.08554 \\
& B & 26 & 25.5769 & 4.65767 & .91344 \\
& C & 35 & 29.3714 & 5.88160 & .99417 \\
& Total & 86 & 27.3256 & 5.61394 & .60537 \\
& & & & & \\
\hline TE & A & 25 & 65.0400 & 7.29429 & 1.45886 \\
& B & 26 & 66.9615 & 8.19503 & 1.60718 \\
& C & 35 & 73.4571 & 9.71458 & 1.64206 \\
& Total & 86 & 69.0465 & 9.30516 & 1.00340 \\
& & & & & \\
\hline
\end{tabular}

The items on the research survey from the shortened version of the Teacher Efficacy Scale (Gibson \& Dembo, 1984) that were factor loaded on the construct of personal teaching efficacy (PTE) yielded the PTE score. Similarly, the items on the survey factor loaded on the construct of general teaching efficacy (GTE) yielded the GTE score. The total efficacy (TE) score was a sum of the PTE and GTE scores.

\section{Research Questions 1, 2 and 3}

Table 12 displays the results of the one-way ANOVA based on frequency of mastery experiences. These results were used to answer research questions 1,2 , and 3 . 
Table 12

One-way Analysis of Variance- Frequency of Mastery Experiences and Efficacy

\begin{tabular}{lccccc}
\hline & Sum of Squares & df & Mean Square & F & Sig. \\
\hline PTE & & & & & \\
Between Groups & 417.846 & 2 & 208.923 & 7.581 & .001 \\
Within Groups & 2287.457 & 83 & 27.560 & & \\
Total & 2705.302 & 85 & & & \\
& & & & & \\
GTE & & & & & \\
Between Groups & 253.326 & 2 & 126.663 & 4.334 & .016 \\
Within Groups & 2425.558 & 83 & 29.224 & & \\
Total & 2678.884 & 85 & & & \\
\hline TE & & & & & \\
Between Groups & 1195.207 & 2 & 597.603 & 8.046 & .001 \\
Within Groups & 6164.607 & 83 & 74.272 & & \\
Total & 7359.814 & 85 & & & \\
& & & & & \\
\hline
\end{tabular}

Research Question 1: Are differences in the frequency of mastery experiences related to differences in personal teaching efficacy?

To answer research question 1 , the researcher used the significance, or $p$-value which is based on the F value, for the between groups comparison on Personal Teaching Efficacy, based on the frequency of each of the three groups' mastery experiences with students with disabilities. The higher the F-value, the lower the $p$-value will be. The Fvalue of 7.58, associated with the $p$-value of .001for this comparison is less than the established statistical significance level of $p<.05$ for this study. This indicates that, for the participants in this study, the frequency of mastery experiences was related to differences in personal teaching efficacy for students with disabilities and the null hypothesis can be disproved. 
In general, the null hypothesis is the hypothesis that the researcher attempts to disprove or reject. In this case, the null hypothesis would state that there is no difference in the means for Groups A, B and C for their mastery experiences when compared to their means for personal teaching efficacy. However, the F-value and associated $p$-value allow us to disprove the null hypothesis, meaning that there is a statistical difference between the means of Groups A, B and C for mastery experiences when compared to the means for their personal teaching efficacy. In other words, the higher frequency of reported mastery experiences of survey respondents corresponded to higher personal teaching efficacy concerning students with disabilities.

Research Question 2: Are differences in the frequency of mastery experiences related to differences in general teaching efficacy?

To answer research question 2, the researcher used the significance, or $p$-value, for the between groups comparison on General Teaching Efficacy, based on the frequency of each of the three groups' mastery experiences with students with disabilities. The F-value of 4.334 and the associated $p$ - value for this comparison of .016 is less than the established statistical significance level of $p<.05$ for this study. This indicates that, for the participants in this study, the frequency of mastery experiences was significantly related to differences in General Teaching Efficacy for students with disabilities. In other words, higher frequency of reported mastery experiences of survey respondents corresponded to higher general teaching efficacy concerning students with disabilities. Again, the null hypothesis can be rejected.

Research Question 3: Are differences in the frequency of mastery experiences related to differences in total teaching efficacy? 
To answer research question 3 , the researcher used the significance, or $p$-value, for the between groups comparison on Total Teaching Efficacy, based on the frequency of each of the three groups' mastery experiences with students with disabilities. The Fvalue of 8.046 and the associated $p$-value of .001 is less than the established statistical significance level of $p<.05$ for this study. This indicates that, for the participants in this study, the frequency of mastery experiences was significantly related to differences in Total Teaching Efficacy for students with disabilities. Once again, the null hypothesis can be rejected. In other words, higher frequency of reported mastery experiences of survey respondents corresponded to higher total teaching efficacy concerning students with disabilities.

\section{One-way Analysis of Variance (ANOVA) - Vicarious Experiences and Efficacy}

Another one-way analysis of variance (ANOVA) was run comparing the three groups established by the mean scores on the answers to the question measuring frequency of vicarious experiences to their mean scores on the Teacher Efficacy scale questions on the research survey. Table 13 displays the descriptive statistics for the results of the one-way ANOVA for vicarious experiences.

Table 13

One-way Analysis of Variance: Frequency of Vicarious Experiences and EfficacyDescriptive Statistics

\begin{tabular}{lllllr}
\hline & & N & Mean & SD & \multicolumn{1}{l}{ SE } \\
\hline PTE & 2.00 & 37 & 40.4054 & 5.32530 & .87547 \\
& 3.00 & 34 & 42.1176 & 5.30731 & .91020 \\
& 4.00 & 15 & 44.0667 & 6.56252 & 1.69444 \\
& Total & 86 & 41.7209 & 5.64155 & .60834 \\
\hline GTE & 2.00 & 37 & 26.9730 & 5.03039 & .82699 \\
& 3.00 & 34 & 27.1176 & 6.42328 & 1.10158
\end{tabular}


Table 13 (continued)

\begin{tabular}{llllrr}
\hline & & $\mathrm{N}$ & Mean & \multicolumn{1}{l}{ SD } & \multicolumn{1}{l}{ SE } \\
\hline GTE & 4.00 & 15 & 28.6667 & 5.16398 & 1.33333 \\
(cont) & Total & 86 & 27.3256 & 5.61394 & .60537 \\
\hline TE & 2.00 & 37 & 67.3784 & 8.43060 & 1.38598 \\
& 3.00 & 34 & 69.2353 & 9.31944 & 1.59827 \\
& 4.00 & 15 & 72.7333 & 10.78005 & 2.78340 \\
& Total & 86 & 69.0465 & 9.30516 & 1.00340 \\
\hline
\end{tabular}

Again, the items on the research survey from the shortened version of the Teacher Efficacy Scale (Gibson \& Dembo, 1984) that were factor loaded on the construct of Personal Teaching Efficacy (PTE) yielded the PTE score. Similarly, the items on the survey factor loaded on the construct of General Teaching Efficacy (GTE) yielded the GTE score. The Total Efficacy (TE) score was a sum of the PTE and GTE scores.

\section{Research Questions 4, 5 and 6}

Table 14 displays the results of the one-way ANOVA based on frequency of vicarious experiences. This data was used to answer research questions 4, 5 and 6 . Table 14

One-Way Analysis of Variance: Frequency of Vicarious Experiences and Efficacy

\begin{tabular}{|c|c|c|c|c|c|}
\hline & Sum of Squares & df & Mean Square & $\mathrm{F}$ & Sig. \\
\hline \multicolumn{6}{|l|}{ PTE } \\
\hline Between Groups & 151.921 & 2 & 75.960 & 2.469 & .091 \\
\hline Within Groups & 2553.382 & 83 & 30.764 & & \\
\hline Total & 2705.302 & 85 & & & \\
\hline \multicolumn{6}{|l|}{ GTE } \\
\hline Between Groups & 33.048 & 2 & 16.524 & .518 & .597 \\
\hline Within Groups & 2645.836 & 83 & 31.878 & & \\
\hline Total & 2678.884 & 85 & & & \\
\hline
\end{tabular}


Table 14 (continued)

\begin{tabular}{lcccccc}
\hline & Sum of Squares & df & Mean Square & F & Sig. \\
\hline TE & & & & & & \\
Between Groups & 308.060 & 2 & 154.030 & 1.813 & .170 \\
Within Groups & 7051.754 & 83 & 84.961 & & \\
Total & 7359.814 & 85 & & & \\
\hline
\end{tabular}

Research Question 4: Are differences in the frequency of vicarious experiences related to differences in personal teaching efficacy?

To answer research question 4, the researcher used the significance, or $p$-value, for the between groups comparison on personal teaching efficacy, based on the frequency of each of the three groups' vicarious experiences with students with disabilities. The Fvalue of 2.469 and associated $p$-value of .091 for this comparison is more than the established statistical significance level of $p<.05$ for this study. This indicates that, for the participants in this study, the frequency of vicarious experiences was not significantly related to differences in personal teaching efficacy for students with disabilities. The null hypothesis cannot be rejected. In other words, higher frequency of reported vicarious experiences of survey respondents did not correspond to higher personal teaching efficacy concerning students with disabilities.

Research Question 5: Are differences in the frequency of vicarious experiences related to differences in general teaching efficacy?

To answer research question 5, the researcher used the significance, or $p$-value, for the between groups comparison on general teaching efficacy, based on the frequency of each of the three groups' vicarious experiences with students with disabilities. The Fvalue of .518 and the associated $p$-value of .597 for this comparison is well above the 
established statistical significance level of $p<.05$ for this study. This indicates that, for the participants in this study, the frequency of vicarious experiences was not significantly related to differences in general teaching efficacy for students with disabilities. Once again, the null hypothesis cannot be rejected. In other words, higher frequency of reported vicarious experiences of survey respondents did not correspond to higher general teaching efficacy concerning students with disabilities.

Research Question 6: Are differences in the frequency of vicarious experiences related to differences in total teaching efficacy?

To answer research question 6 , the researcher used the significance, or $p$-value, for the between groups comparison on total teaching efficacy, based on the frequency of each of the three groups' vicarious experiences with students with disabilities. The Fvalue of 1.813 and the associated $p$-value of .170 for this comparison is more than the established statistical significance level of $p<.05$ for this study. This indicates that, for the participants in this study, the frequency of vicarious experiences was not significantly related to differences in Total Teaching Efficacy for students with disabilities. Once again, the null hypothesis could not be rejected. In other words, higher frequency of reported vicarious experiences of survey respondents did not correspond to higher total teaching efficacy concerning students with disabilities.

\section{Research questions 7, 8 and 9}

Table 15 displays the results of the ANCOVA based on frequency of social persuasion experiences and personal teaching efficacy that were used to answer research question 7. 
Table 15

Results of the ANCOVA for Personal Teaching Efficacy

\begin{tabular}{llllll}
\hline & $\begin{array}{l}\text { Type III } \\
\text { Sums of Squares }\end{array}$ & df & Mean Square & F & sig. \\
\hline Social Persuasion & 13.702 & 2 & 6.851 & .233 & .793 \\
Years of Experience & 273.271 & 1 & 273.271 & 9.295 & .003 \\
Corrected Model & 294.614 & 3 & 98.205 & 3.340 & .023 \\
\hline
\end{tabular}

Research question 7: Are differences in the frequency of social persuasion experiences related to differences in personal teaching efficacy?

To answer research question 7 a one-way between groups analysis of covariance was conducted to compare the personal teaching efficacy scores of Groups A, B and C, categorized according to their answer on the social persuasion question of the survey. The independent variable was the frequency of social persuasion experiences and the dependent variable was personal teaching efficacy. Years of teaching experience with students with disabilities was the covariate, or the variable that was controlled for. After controlling for the covariate, there was not a significant difference between Groups A, B and $\mathrm{C}$ on their personal teaching efficacy, based on frequency of social persuasion experiences as indicated by the F-value of .233 and the associated $p$-value of .793. The $p$-value, or significance level, for this comparison is greater than the established statistical significance level of $p<.05$ for this study. This means that, for the participants in this study, the frequency of social persuasion experiences was not significantly related to differences in personal teaching efficacy for students with disabilities, when years of experience were controlled for. 
Table 16 displays the results of the ANCOVA based on frequency of social persuasion experiences and general teaching efficacy that were used to answer research question 8 .

Table 16

Results of the ANCOVA for General Teaching Efficacy

\begin{tabular}{llllll}
\hline & $\begin{array}{l}\text { Type III } \\
\text { Sums of Squares }\end{array}$ & df & Mean Square & F & sig. \\
\hline Social Persuasion & 70.004 & 2 & 35.002 & 1.106 & .336 \\
Years of Experience & 17.528 & 1 & 17.528 & .554 & .459 \\
Corrected Model & 84.807 & 3 & 28.269 & .894 & .448 \\
\hline
\end{tabular}

Research question 8: Are differences in the frequency of social persuasion experiences related to differences in general teaching efficacy?

To answer research question 8 a one-way between groups analysis of covariance was conducted to compare the general teaching efficacy scores of Groups A, B and C, categorized according to their answer on the social persuasion question of the survey. The independent variable was the frequency of social persuasion experiences and the dependent variable was general teaching efficacy. Years of teaching experience with students with disabilities was the covariate, or the variable that was controlled for. After adjusting for years of experience, there was not a significant difference between Groups $\mathrm{A}, \mathrm{B}$ and $\mathrm{C}$ on their general teaching efficacy, based on frequency of social persuasion experiences as indicated by the F-value of 1.106 and the associated $p$-value of .336. The $p$-value, or significance level, for this comparison is greater than the established statistical significance level of $p<.05$ for this study. This means that, for the participants in this 
study, the frequency of social persuasion experiences was not significantly related to differences in general teaching efficacy for students with disabilities, when years of experience were controlled for.

Table 17 displays the results of the ANCOVA based on frequency of social persuasion experiences and total teaching efficacy that were used to answer research question 9.

Table 17

Results of the ANCOVA for Total Teaching Efficacy

\begin{tabular}{llllll}
\hline & $\begin{array}{l}\text { Type III } \\
\text { Sums of Squares }\end{array}$ & df & Mean Square & F & sig. \\
\hline Social Persuasion & 140.644 & 2 & 70.332 & .818 & .445 \\
Years of Experience & 152.381 & 1 & 152.381 & 1.772 & .187 \\
Corrected Model & 307.389 & 3 & 102.463 & 1.191 & .318 \\
\hline
\end{tabular}

Research question 9: Are differences in the frequency of social persuasion experiences related to differences in total efficacy?

To answer research question 9, a one-way between groups analysis of covariance was conducted to compare the total teaching efficacy scores of Groups A, B, and C, categorized according to their answer on the social persuasion question of the survey. The independent variable was the frequency of social persuasion experiences and the dependent variable was total teaching efficacy. Once again, years of teaching experience with students with disabilities was the covariate, or the variable that was controlled for. After adjusting for years of experience, there was not a significant difference between Groups A, B, and C on their total teaching efficacy, based on frequency of social 
persuasion experiences as indicated by the F-value of .818 and the associated $p$-value of .445. The $p$-value, or significance level, for this comparison is greater than the established statistical significance level of $p<.05$ for this study. This means that, for the participants in this study, the frequency of social persuasion experiences was not significantly related to differences in total teaching efficacy for students with disabilities, when years of experience were controlled for.

\section{Post-hoc Analysis}

The researcher ran Post-hoc comparisons using the Scheffe test to determine where differences existed between means for the groups created using frequency of mastery scores. The Scheffe test was chosen because it is the most frequently used with ANOVA and is the most conservative post-hoc comparison. Table 16 shows the results of the Post-hoc comparisons. Each of the three groups, created based on answers to the frequency of mastery experiences question on the survey, was compared to the means of the other groups to determine where statistically significant differences existed. The ANOVA analysis established that statistical differences existed in teaching efficacy concerning students with disabilities between these three groups. The Scheffe test was run to determine where those differences existed. 
Table 18

Post-hoc Comparison using the Scheffe Test

\begin{tabular}{lccccc}
\hline \multirow{2}{*}{ Dep. Variable } & Mastery & Mastery & Mean Diff. & SE & Sig. \\
\hline PTE & Group A & 3.00 & -2.62462 & 1.47050 & .210 \\
& & 4.00 & -5.32571 & 1.37470 & $.001^{*}$ \\
& Group B & 2.00 & 2.62462 & 1.47050 & .210 \\
& & 4.00 & -2.70110 & 1.35919 & .145 \\
& Group C & 2.00 & 5.32571 & 1.37470 & $.001^{*}$ \\
& & 3.00 & 2.70110 & 1.35919 & .145 \\
GTE & & & & \\
& Group A & 3.00 & .70308 & 1.51 .424 & .898 \\
& & 4.00 & -3.09143 & 1.41 .559 & .098 \\
& Group B & 2.00 & -.70308 & 1.51424 & .898 \\
& & 4.00 & -3.79451 & 1.39962 & $.030^{*}$ \\
& Group C & 2.00 & 3.09143 & 1.41559 & .098 \\
& & 3.00 & 3.79451 & 1.39962 & $.030^{*}$ \\
& & & & & .729 \\
& Group A & 3.00 & -1.92154 & 2.41403 & $.002^{*}$ \\
& & 4.00 & -8.41714 & 2.25676 & .729 \\
& Group B & 2.00 & 1.92154 & 2.41403 & $.018^{*}$ \\
& & 4.00 & -6.49560 & 2.23130 & $.002^{*}$ \\
& Group C & 2.00 & 8.41714 & 2.25676 & $.018^{*}$ \\
\hline & 3.00 & 6.49560 & 2.23130 & & \\
\hline
\end{tabular}

*The mean difference is significant at the 0.05 level

The results of the post-hoc test indicate that there were significant differences in personal teaching efficacy between Group B and Group C based on the frequency of mastery experiences. The scale given on the survey was $1=$ Never (No experiences per year) and 4= Frequently (3-4 experiences per year). As previously reported, the groups that answered 1 and 2 were compressed into one group for the one-way ANOVA on mastery experiences, which is Group A.

For general teaching efficacy, the post-hoc test results reflect significant differences between Group B and the Group C for frequency of mastery experiences. 
Finally, the results of the post-hoc test indicate that for total teaching efficacy, a significant difference lay between Group A and Group C for frequency of mastery experiences. Additionally, there was a significant difference in total teaching efficacy between Group B and Group C for frequency of mastery experiences.

\section{Additional Findings}

Additional findings of this study included the percentage of respondents who reported participating in mastery and vicarious experiences involving students with disabilities. The questions on the survey that measured the extent to which participants had engaged in experiences attached the following qualifiers to answer values; $1=$ Never (No times per year) to $4=$ Frequently (3-4 times per year). No descriptors were attached to answers of 2 or 3 .

Respondents' answers to the question on mastery experiences indicated that 40.7\% had participated in mastery experiences with students with disabilities 3-4 times per year in the last year. However, their answers to the survey question on vicarious experiences with students with disabilities indicated that only $17.4 \%$ had participated in these types of experiences 3-4 times per year in the last year. Furthermore, only $8.1 \%$ of participants reported having 3-4 social persuasion experiences per year with students with disabilities. A greater portion of teachers in the survey indicated never having had vicarious experiences with students with disabilities in the last year $(10.5 \%)$ when compared with the portion of teachers reporting that they had no mastery experiences with students with disabilities in the last year (2.3\%). Even more notable, the percentage of general education teachers reporting that they had no social persuasion experiences concerning students with disabilities in the last year was $31.4 \%$. As previously 
mentioned, additional course work and professional development training about students with disabilities are examples of social persuasion experiences. 


\section{Chapter 5}

\section{Summary and Discussion}

The purpose of this chapter is to summarize and discuss the findings of this study. In this section, the reader will find a summary of the purpose, the problem, and the rationale of the study. The relevant literature used as the basis for this study will be summarized. Additionally, a summary of the findings will be discussed and organized around the research questions. Finally, implications for practitioners and suggestions for further research will be discussed.

\section{Review of the Purpose, Problem and Rationale}

The purpose of this study was to examine if the frequency of teachers' experiences, based on Bandura's (1977) sources of efficacy (mastery, vicarious, social persuasion), is related to differences in their teaching efficacy beliefs concerning students with disabilities.

This study evolved from the problem that although students with disabilities are spending more of the school day in the general education classroom, the majority of general education teachers report feeling unprepared to meet the needs of these students, indicating possible low teaching efficacy for students with disabilities. Additionally, the performance of students with disabilities on high stakes state tests has lagged behind the performance of their peers. Teacher efficacy, which is a belief, is associated with certain teacher behavior. These teacher behaviors, then, correlate to higher student achievement. 
Increasing teacher efficacy of general education teachers regarding students with disabilities may be one pathway to closing the achievement gap for these students.

Bandura (1977) theorized that there are four sources of self-efficacy: mastery experiences, vicarious experiences, social persuasion experiences, and affective state experiences. Research has shown that efficacy is malleable through professional development experiences that encompass Bandura's identified sources of self-efficacy. Teaching efficacy is a construct based on the concept of self-efficacy.

Proposed directions for future research on teacher efficacy have included further investigation on these sources of efficacy, specifically how these experiences function in practice. Bandura's sources of efficacy are a theory, but few studies test that theory out. Additionally, Bandura suggested studying efficacy in specific domains, such as math efficacy or science efficacy (Klasson et al., 2011). Some research has been done in domain specific efficacy (Buss, 2010; Corkett, Hatt, \& Benevides, 2011). Keeping that in mind and with consideration of the data on the achievement of students with disabilities on high stakes state tests, examining general education teachers' efficacy regarding students with disabilities in their classrooms would be such a domain specific area and would respond to a current need. There has been little research on how support can be provided to increase efficacy of experienced teachers, especially in the case of working with students with disabilities.

Determining the trajectory of teaching efficacy beliefs over time and how malleable they are is an area lacking in the literature (Tschannen-Moran et al., 1998). 
Understanding if the frequency of experiences contributes to general teachers' efficacy beliefs regarding students with disabilities can help determine which professional development experiences are the most powerful in increasing this efficacy, and thereby, in improving instructional practice and student achievement in inclusionary settings.

The following questions guided the research and were matched to the primary purpose of this study:

1. Are differences in the frequency of mastery experiences related to differences in personal teaching efficacy?

2. Are differences in the frequency of mastery experiences related to differences in general teaching efficacy?

3. Are differences in the frequency of mastery experiences related to differences in total teaching efficacy?

4. Are differences in the frequency of vicarious experiences related to differences in personal teaching efficacy?

5. Are differences in the frequency of vicarious experiences related to differences in general teaching efficacy?

6. Are differences in the frequency of vicarious experiences related to differences in total teaching efficacy?

7. Are differences in the frequency of social persuasion experiences related to differences in personal teaching efficacy?

8. Are differences in the frequency of social persuasion experiences related to differences in general teaching efficacy? 
9. Are differences in the frequency of social persuasion experiences related to differences in total teaching efficacy?

\section{Summary of the Relevant Literature}

The history of special education legislation and litigation was examined in the context of a general shift towards the use of an inclusion model for educating students with disabilities. The review included research on the outcomes of inclusion for students with disabilities. This body of research is lacking in breadth and yields contradictory findings, leading to a continuing controversy over the benefits of inclusion for students with disabilities, specifically when academic achievement is studied. This lack of evidence in the literature exists despite the fact that a greater number of students with disabilities are included in the general education classroom for the majority of the instructional day.

The literature on the theories underlying the concept of teacher efficacy was examined. Teacher efficacy rests on the theories of Rotter (1966) and Bandura (1977). Rotter's social learning theory provides the theoretical concept of locus of control, and Bandura's social cognitive theory provides the theoretical concept of agency and sources of self-efficacy.

There was extensive literature that indicated that certain behaviors are associated with teacher efficacy. These teacher behaviors included those having to do with classroom management strategies, instructional strategies and student- teacher relationships (Ashton \& Webb, 1986). Differences were noted in the literature between the behaviors and instructional decisions of teachers with high efficacy and those with low efficacy. The behaviors of teachers with high efficacy were further associated with 
higher academic achievement. The overlap between teacher behaviors associated with high efficacy and those associated with student achievement were examined (TschannenMoran et al., 1998).

The literature surrounding the teaching efficacy of general education teachers regarding inclusion of students with disabilities was also examined. Overall, the literature pointed to a majority of general education teachers supporting inclusion as a philosophy, but feeling unprepared to meet the needs of students with disabilities placed in their class (Buell et al., 1999; Scruggs \& Mastropieri, 1996). General education teachers with high efficacy were more likely to prefer collaborative work relationships, like those found working with a special education teacher in an inclusion classroom (Coladarci \& Breton, 1997). They were also more likely to believe that students who were culturally and linguistically diverse along with students with disabilities belonged in the general education classroom (Chu, 2011; Soodak \& Podell, 1993). They were less likely to refer struggling students for special education. General education teachers with high efficacy were less anxious about inclusion of students with disabilities in their class (Gotshall \& Stefanou, 2011).

The literature on the Teacher Efficacy Scale (Gibson \& Dembo, 1984), one measure of teaching efficacy, was examined. The research behind the construct validation of teacher efficacy and the teacher behaviors that correlate with high and low scores on the Teacher Efficacy Scale were noted. The rationale and literature supporting the use of the shortened version of the Teacher Efficacy Scale was included.

Current theories that use self-efficacy as their basis were included. Literature on Duckworth and colleagues' (2007) theory of “grit", and Dweck's (2006) theory of 
"mindset" was examined in the light of Bandura's cognitive learning theory. Areas of overlap with the concept of teaching efficacy were noted.

Finally, the review included a look at how and if teaching efficacy can be changed. The research on the antecedents of teacher efficacy, both in terms of Bandura's (1977) theorized sources of efficacy and in terms of professional development were included in this section. Literature on the malleability of teacher efficacy was not extensive and in some cases, was contradictory. It did point to years of teaching experience as a variable that has an effect on teacher efficacy.

The existing literature that clearly examines Bandura's (1977) sources of efficacy and how they can applied to increasing teacher efficacy is not extensive. The research does consistently point to the strength of mastery experiences in affecting teaching efficacy, with some studies indicating that vicarious experiences and social persuasion experiences also affect teacher efficacy, although not as powerfully as mastery experiences. Much of the research on Bandura's sources of efficacy has been applied in pre-service settings.

Professional development research has been applied to changing in-service teaching efficacy. The literature in this area found that coaching was a powerful tool for changing teacher behaviors, specifically as they relate to instruction and implementation of new strategies (Joyce \& Showers, 2002). Additionally, professional development that is directed at known sources of efficacy, such as those proposed by Bandura (1977), can contribute to improved instructional skills, higher confidence, and resulting higher teaching efficacy (Ross \& Bruce, 2007). Finally, literature was included on the beneficial 
outcomes of job-embedded professional development in terms of improving instructional practice and student achievement (Darling-Hammond \& Richardson, 2009).

In summary, the literature review supported that conceptual framework of this study: that teaching efficacy affects behaviors that are associated with student achievement, that general education teachers may have low teaching efficacy for inclusion of students with disabilities, and that experiences theorized to be sources of efficacy may be related to general education teachers' efficacy regarding students with disabilities.

\section{Summary of the Study Methodology}

The research design for this study was both descriptive and correlational. Survey methodology was used to gather the data needed for the analysis. The unit of measurement was the individual teacher.

The shortened, 16-item version of the Teacher Efficacy Scale (Gibson \& Dembo, 1984) amended to reflect teachers' sense of efficacy concerning students with disabilities was used to measure the dependent variable, teaching efficacy of general education teachers regarding students with disabilities. Four additional survey questions measured the independent variable, the frequency of experiences (mastery, vicarious, and verbal persuasion) teachers had participated in during the last year. Although data was collected on the frequency of affective state experiences, this data was not analyzed as part of this study because the literature did not support a strong effect on teaching efficacy.

ANOVA was used to answer the first six research questions because both frequency of mastery experiences and frequency of vicarious experiences were positively 
correlated with years of teaching experience. However, in the analysis of verbal persuasion experiences, there was no correlation with years of teaching experience, so ANCOVA was used to answer the final three research questions.

\section{Findings and Discussion}

The study findings are organized by research questions. Research questions are grouped according to type of experience (mastery, vicarious, verbal persuasion). A discussion of the findings follows.

\section{Findings for Research Questions 1, 2 and 3}

Research question 1: Are differences in the frequency of mastery experiences related to differences in personal teaching efficacy?

Research question 2: Are differences in the frequency of mastery experiences related to differences in general teaching efficacy?

Research question 3: Are differences in the frequency of mastery experiences related to differences in total teaching efficacy?

Because years of teaching experience correlated to frequency of mastery experiences, a one-way between groups analysis of variance explored the effect of frequency of mastery experiences on personal teaching efficacy, general teaching efficacy and total teaching efficacy, as measured by the shortened version of the Teacher Efficacy Scale (Gibson \& Dembo, 1984). In this study, the Teacher Efficacy Scale was amended to reflect students with disabilities. Participants were divided into three groups based on their answer to the question measuring frequency of mastery experiences. There was a statistically significant difference at the $p<.05$ level in the scores on the Teacher Efficacy Scale for the three groups (Personal Teaching Efficacy, $p=.001$; 
General Teaching Efficacy, $p=.016$; Total Teaching Efficacy, $p=.001$ ). Frequency of mastery experiences was related to different levels of teacher efficacy (personal, general and total) concerning students with disabilities.

Post-hoc comparisons using the Scheffe test were conducted to see where the significant differences existed. As previously noted, the groups answering 1 or 2 were compressed into one group. An answer of 1 on the mastery question indicated no instances of a mastery experience in the last year. An answer of 4 reflected 3-4 instances of mastery experiences in the previous year.

The Post-hoc comparison indicated that the mean score for the group answering 1 or 2 (Group A) and the mean score for the group answering 4 (Group C) for frequency of mastery experiences differed significantly on personal teaching efficacy $(p=.001)$. The post-hoc comparisons also reflected significant differences between the mean score for the group that answered 3 (Group B) and the mean score for the group that answered 4 (Group C) for frequency of mastery experiences on general teaching efficacy $(p=.030)$. Finally, for total efficacy, there was a significant difference in the mean score of the group that answered 3 (Group B) and the group that answered 4 (Group C) for frequency of mastery scores $(p=.002)$ and a significant difference between the group that answered 3 (Group B) and the group that answered 4 (Group C) for frequency of mastery experiences $(p=0.18)$.

\section{Findings for Research Questions 4, 5 and 6}

Research question 4: Are differences in the frequency of vicarious experiences related to differences in personal teaching efficacy? 
Research question 5: Are differences in the frequency of vicarious experiences related to differences in general teaching efficacy?

Research question 6: Are differences in the frequency of vicarious experiences related to differences in total teaching efficacy?

Because years of teaching experiences was also found to correlate to frequency of vicarious experiences, a one-way between groups analysis of variance was conducted to explore the effect of frequency of vicarious experiences on personal teaching efficacy, general teaching efficacy, and total teaching efficacy, as measured by the shortened version of the Teacher Efficacy Scale (Gibson \& Dembo, 1984) amended to reflect students with disabilities. Participants were divided into three groups based on their answers to the question measuring frequency of vicarious experiences.

There was no statistically significant difference at the $p<.05$ level in the scores on the Teacher Efficacy Scale for the three groups (Personal Teaching Efficacy, $p=.091$; General Teaching Efficacy, $p=.597$; Total Teaching Efficacy, $p=170$ ) based on frequency of vicarious experiences. Frequency of vicarious experiences was not correlated to differences in personal teaching efficacy, general teaching efficacy or total teaching efficacy between the three groups established for this analysis.

\section{Findings for Research questions 7, 8 and 9}

Research question 7: Are differences in the frequency of social persuasion experiences related to differences in personal teaching efficacy?

Research question 8: Are differences in the frequency of social persuasion experiences related to differences in general teaching efficacy? 
Research question 9: Are differences in the frequency of social persuasion experiences related to differences in total teaching efficacy?

In the case of years of teaching experience and social persuasion experiences, a correlation was not found, so years of experience had to be controlled for in this analysis. Therefore, a one-way analysis of covariance (ANCOVA)was conducted to explore the impact of frequency of social persuasion experiences on personal teaching efficacy, general teaching efficacy, and total teaching efficacy, as measured by the shortened version of the Teaching Efficacy Scale (Gibson \& Dembo, 1984) when years of experience teaching students with disabilities was controlled for.

Participants were divided into three groups based on their answers to question measuring frequency of social persuasion experiences. There was not a statistically significant difference at the $p<.05$ level in the scores on the Teacher Efficacy Scale for the three groups on Personal Teaching Efficacy ( $p=.793)$, General Teaching Efficacy $(p=.336)$ or Total Teaching Efficacy $(p=.445)$. For participants in this study, the frequency of verbal persuasion experiences was not related to differences in teaching efficacy concerning students with disabilities even when years of teaching experience were controlled for.

\section{Discussion}

The analyses of variance used to answer the research questions and to address the study purposes yielded mixed results. The frequency of mastery experiences was the only statistically significant variable related to levels of teaching efficacy concerning students with disabilities. This does support the literature that mastery experiences are 
the most powerful sources of efficacy (Bandura, 1977; Bandura, 1998; Bandura, 2006; Putnam, 2012).

In the limited literature examining the exact nature of teaching efficacy sources, mastery experiences are based on actual, authentic and successful teaching practices (Bautista, 2011). In addition to being limited in scope, most research on the nature and strength of mastery experiences has been done at the pre-service stage. Few studies have examined the nature of mastery experiences and how they act as sources of teaching efficacy for in-service teachers.

Bautista (2011) provided more precise examples of mastery experiences for preservice teachers. In his research, interviewing a student to determine his or her understanding of a concept was an example of a mastery experience. When a teacher created a lesson that was successful and then reflected on their instructional practice, this too, could be a mastery experience. For the purposes of this study, a mastery experience was defined as a successful experience or lesson with a student with a disability. Perhaps the difficulty in precisely defining a mastery experience is part of the reason there is not more research in this area.

According to Tschannen- Moran and Woolfolk Hoy (2001), professional development of in-service teachers should be developed as strong mastery experiences with the intent of helping teachers gain evidence of improved learning outcomes for their students in order to facilitate the established teaching efficacy pay off that would ensue. So, orchestrating mastery experiences for in-service teachers that enable them to see tangible success with students with disabilities would, based on the literature and the 
results of this study, improve their teaching efficacy for these students in inclusion classrooms.

Additionally, it should be noted that mastery experiences were strongly correlated to years of experience teaching students with disabilities in this study. It is hard to determine if the differences in teaching efficacy of the participants in this study were due more to years of experience teaching students with disabilities or to increased frequency of mastery experiences. It is possible that just by the nature of additional years of experience; a teacher has more mastery experiences with students with disabilities.

The results of this study with regards to vicarious experiences and social persuasion experiences do not support the literature that says that both these types of experiences are also sources of efficacy (Bandura, 1977; Bandura, 1998; Bautista, 2011; Buss, 2010; Ross \& Bruce, 2007; Tschannen-Moran et al., 1998). In the literature, precise examples of vicarious and social persuasion experiences are more prevalent, although once again, much of the research has been done on pre-service teachers.

This study found that the frequency of vicarious experiences was not related to differences in teaching efficacy (personal, general, or total) concerning students with disabilities. Vicarious experiences were identified as those in which one observes another teaching. Some examples of vicarious experiences are collaborative learning visits (groups of teacher observe in another classroom and then reflect on those observations), sharing and discussion of work in collaborative learning teams, and watching a video of self or another teaching (Bautista, 2011; Darling-Hammond \& Richardson, 2007; Putnam, 2012; Ross \& Bruce, 2007; Tshannen-Moran et al., 1998) 
Social persuasion experiences, like vicarious experiences, are more clearly described in the literature. Coursework is considered a type of social persuasion experience (Tschannen-Moran et al., 1998) and taking more classes about students with disabilities has been theorized to increase teaching efficacy for these students (Yellin et al., 2003). Specific performance feedback from colleagues or supervisors is also considered to be a social persuasion experience. For the purposes of this study, social persuasion experiences included working with a coach and participating in a study group that examines current research (Bautista, 2011; Darling-Hammond \& Richardson, 2009; Joyce \& Showers, 2002; Putnam, 2012).

Not only is the research on the specific nature of efficacy sources limited, but studies examining the teaching efficacy of general education teachers working in inclusion classrooms are largely missing from the literature. This is an important area that needs to be delved into given the achievement gap between students with disabilities and their general education peers on high stakes state tests.

In this study, neither vicarious nor social persuasion experiences were found to be significantly related to differences in personal teacher efficacy, general teacher efficacy, or total teaching efficacy at the $p<.05$ level concerning students with disabilities. One possible explanation for these results is the variation in frequency of experiences reported by survey participants. In table 8 , survey respondents indicating that their frequency of mastery experiences was 3-4 times per year was $40.7 \%$. Only $2.3 \%$ of survey respondents reported having no mastery experiences with students with disabilities in the past year. 
Conversely, the frequency data on both vicarious experiences and social persuasion experiences indicated that fewer respondents had participated in these types of experiences at the 3-4 times per year level. In table 9, the frequency of vicarious experiences for survey respondents was only $17.4 \%$ at the 3-4 times per year level. Similarly, in table 10, the frequency of social persuasion experiences for survey respondents was only $8.1 \%$ at the $3-4$ times per year level. General education teachers in this study reported a much higher frequency of mastery experiences than either vicarious or verbal persuasion experiences and perhaps this affected how much these types of experiences acted as sources of teaching efficacy. Additionally, the definition and examples provided for each of the experience questions on the survey may have affected the participants' answers to these questions.

In general, the conceptual framework of this study, that the experiences that Bandura (1977) identified as sources of efficacy do affect teaching efficacy, was partially supported. For the participants of this study, it appears that mastery experiences are, indeed, powerful sources of teaching efficacy especially in the case of general education teachers working with students with disabilities in inclusion classrooms. However, the relationship between the frequency of vicarious experiences and social persuasion experiences and teaching efficacy was not supported for the participants in this study. The challenge for school leaders is how to develop a more precise understanding of what constitutes and promotes mastery experiences for general education teachers working with students with disabilities. 


\section{Recommendations for Practice}

The literature repeatedly supports the concept of teacher efficacy and its relationship to teacher behaviors. These teacher behaviors include the manner in which student relationships are navigated, the classroom management strategies that are implemented, and the specific instructional strategies that are chosen (Ashton \& Webb, 1986). These teacher behaviors correlate to improved student achievement. Bandura (1977) theorized that certain types of experiences act as sources of efficacy. It is important for school leaders to understand which experiences are related to increases in teaching efficacy in order to impact change in student achievement, specifically in the case of students with disabilities. Additionally, the frequency of experiences does not necessarily factor in the quality of experiences, and this is a variable that is important to keep in mind.

The results of this study indicate that mastery experiences are significantly related to differences in personal teaching efficacy, general teaching efficacy, and total teaching efficacy for general education teachers with regards to students with disabilities. These results mean that it is important for school leaders to determine how to provide professional development opportunities that lead to mastery experiences for general education teachers working with students with disabilities. The following recommendations for future research may lead to a better understanding of how that can be done.

\section{Recommendations for Future Research}

Area 1: Conduct qualitative research on mastery experiences: This study supported the theory that mastery experiences act as sources of teaching efficacy. 
However, the nature of these mastery experiences is an area that should be studied in depth. Use of interview methodology and observation may help to develop a rich description of what constitutes a mastery experience that leads general education teachers to develop higher teaching efficacy for students with disabilities. Observation of both general education and special education teachers working with students with disabilities could yield important data on mastery experiences. This data could help school leaders develop professional development opportunities that support increased mastery experiences for general education teachers. Knowing with more precision what precipitates and facilitates a mastery experience for general education teachers working in inclusion classrooms could help tailor professional development that supports and enables such mastery experiences.

Area 2: Use different tools to measure teaching efficacy: This study used the Teacher Efficacy Scale (Gibson \& Dembo, 1984), but there are other tools for measuring teaching efficacy. The Ohio Teacher Sense of Efficacy Scale (Tschannen-Moran \& Woolfolk Hoy, 2001) is one such tool for measuring teacher efficacy. This scale includes items that measure efficacy for instructional strategies, efficacy for classroom management, and efficacy for student engagement. A tool like the Ohio Teacher Sense of Efficacy further refines measurement of different factors associated with teaching efficacy. Future research that uses alternate teacher efficacy measurement tools may give further validity to the findings of this study.

Area 3: Expand the sample size: The sample size of this study was 86 general education teachers. As previously noted, 116 teachers began the survey, but only 86 completed the entire survey. An $\mathrm{N}$ of 86 is small and allows for the possibility of error in 
the results. Future research should be done with a much bigger sample size to determine if vicarious and verbal persuasion experiences are related to teacher efficacy if a larger sample is used.

Area 4: Diversify the sample population: This study was conducted in a large suburban school district. Similar research on the sources of efficacy of general education teachers concerning students with disabilities should be done in rural and urban areas to determine if sources of efficacy differ when context differs. This would also allow for the possibility of generalizing the results of this kind of research.

Area 5: Conduct longitudinal study of teacher efficacy sources: The literature yields contradictory theories on the trajectory of a teacher's efficacy as her career progresses. Longitudinal research that tracks teaching efficacy over the course of time, and specifically concerning students with disabilities, may give us valuable information about which sources are most powerful at different points during a teacher's career. This data could help tailor differentiated professional development opportunities for teachers in order to most powerfully affect their teaching efficacy for students with disabilities. 


\section{References}

Albrecht, S. F., \& Joles, C. (2003). Accountability and access to opportunity: Mutually exclusive tenets under a high-stakes testing mandate. Preventing School Failure, 47(2), 86-91.

Ashton, P.T., \& Webb, R. B. (1986). Making a difference: Teachers'sense of efficacy and student achievement. New York: Longman.

Bandura, A. (1977). Self-efficacy: Toward a unifying theory of behavioral change. Psychological Review, 84, 191-215.

Bandura, A. (1993). Perceived self-efficacy in cognitive development and functioning. Educational Psychologist, 28, 117-148.

Bandura, A. (1998). Personal and collective efficacy in human adaptation and change. In J. Adair, D. Belanger \& K. Dion (Eds.), Advances in psychological science: Vol. 1 Personal, social and cultural aspects (pp. 51-71). Hove, UK: Psychology Press

Bandura, A. (2006). Guidelines for constructing self-efficacy scales. Self-efficacy beliefs of adolescents. Information Age Publishing, 307-337.

Bandura, A., \& Locke, E. A. (2003). Negative self-efficacy and goal effects revisited. Journal of Applied Psychology, 88, 87-99. 
Bautista, N. U. (2011). Investigating the use of vicarious and mastery experiences in influencing early childhood education majors' self-efficacy beliefs. Journal of Science Teacher Education, 22, 333-349.

Bouck, E. (2009). No Child Left Behind, the Individuals with Disabilities Education Act and functional curricula: A conflict of interest? Education and Training in Developmental Disabilities, 44, 3-13.

Buell, M. J., Hallam, R., Gamel-McCormick, M., \& Sheer, S. (1999). A survey of general and special education teachers' perceptions and in-service needs concerning inclusion. International Journal of Disability, Development and Education, 46, $143-156$.

Buss, R. R. (2010). Efficacy for teaching elementary science and mathematics compared to other content. School Science and Mathematics, 110, 290-297.

Center on Education Policy. (2009). Has progress been made in raising achievement for students with disabilities? State test score trends through 2007-08, Part 4. Washington, DC. Retrieved from http://files.eric.ed.gov/fulltext/ED509022.pdf Cole, C. (2006, Fall). Closing the Achievement Gap Series III: What is the impact of NCLB on the inclusion of students with disabilities? (Issue Brief No. 11) Indiana University: Center for Evaluation \& Education Policy. Retrieved from http://files.eric.ed.gov/fulltext/ED495750.pdf.

Chu, S. Y. (2011). Teacher perceptions of their efficacy for special education referral of students from culturally and linguistically diverse backgrounds. Education and Urban Society, 132(1), 3-14. 
Coladarci, T., \& Breton, W. A. (1997). Teacher efficacy, supervision, and the special education resource room teacher. The Journal of Educational Research, 90, 230239.

Corkett, J., Hatt, B., \& Benevides, T. (2011). Student and teacher self-efficacy and the connection to reading and writing. Canadian Journal of Education, 34(1), 65-98.

Cosier, M., Causton-Theoharis, J., Theoharis, G. (2013). Does access matter? Time in general education and achievement for students with disabilities. Remedial and Special Education, 34, 323-332.

Damer, L. K. (2001). Inclusion and the law. Music Educators Journal, 87(4), 19-22.

Darling-Hammond, L., \& Richardson, N. (2009). Research review/teacher learning: What matters? Educational Leadership, 66(5), 46-53.

deBettencourt, L. (1999). General educators' attitudes toward students with disabilities and their use of instructional strategies: Implications for training. Remedial and Special Education, 20(1), 27-35.

Dembo, M. H., \& Gibson, S. (1985). Teachers' sense of efficacy: An important factor in school improvement. The Elementary School Journal, 86, 173-184.

Dibapile, W. T. (2012). A review of literature on teacher efficacy and classroom management. Journal of College Teaching and Learning, 9(2), 79-91.

Duckwork, A. L, Peterson, C., Matthews, M. D., \& Kelly, D. R. ( 2007) Grit: Perseverance and passion for long-term goals. Journal of Personality and Social Psychology, 92, 1087-1101.

Dweck, C. (2006) Mindset: The new psychology of success. New York: Ballantine Books. 
Forlin, C., Earle, C., \& Sharma, U. (2011). The sentiments, attitudes, and concerns about inclusive education revised (SACIE-R) scale for measuring pre-service teachers' perceptions about inclusion. Exceptionality Education International, 21(3), 5065.

Friend, M., Cook, L., Hurley-Chamberlain, D., \& Shamberger, C. (2010). Co-teaching: An illustration of the complexity of collaboration in special education. Journal of Educational and Psychological Consultation, 29, 2-27.

Fuchs, L., Fuchs, D., Craddock, C., Hollenbeck, K., \& Hamlett, C. (2008). Effects of small-group tutoring with and without validated classroom instruction on at-risk students' math problem solving: Are the two tiers of prevention better than one? Journal of Educational Psychology, 100, 491-459.

Gao, W., \& Mager, G. (2011). Enhancing pre-service teachers'sense of efficacy and attitudes toward school diversity through preparation: A case of one U.S. inclusive education program. International Journal of Special Education, 26, 92107.

Gibson, S., \& Dembo, M. H. (1984). Teacher efficacy: A construct validation. Journal of Educational Psychology, 76, 569- 582.

Goddard, R. D., Hoy, W. K., \& Woolfolk Hoy, A. (2004). Collective efficacy beliefs: Theoretical developments, empirical evidence, and future directions. Educational Researcher, 33(3), 3-13.

Gotshall, C., \& Stefanou, C. (2011). The effects of on-going consultation for accommodating students with disabilities on teacher self-efficacy and learned helplessness. Education, 132, 321-331. 
Grskovic, J., \& Trzcinka, S. (2011). Essential standards for preparing secondary content teachers to effectively teach students with mild disabilities in included settings. American Secondary Education, 29(2), 94-106.

Harkins, S. B. (2012). Mainstreaming, the regular education initiative and inclusion as lived experience1974-2004: A practitioner's view. i.e.: Inquiry in Education, $3(1), 1-20$.

Hollenweger, J. (2011). Teachers' ability to assess students for teaching and supporting learning. Prospects, 41, 445-457.

Huai, N., Braden, J. P., White, J. L., \& Elliott, S. N. (2006). Effect of an internet-based professional development program on teachers' assessment literacy for all students. Teacher Education and Special Education, 29, 244-260.

Idol, L. (2006). Towards inclusion of special education students in general education. Remedial and Special Education, 27(2), 77-94.

Itkonen, T. (2007). PL 94-142: Policy, evolution, and landscape shift. Issues in Teacher Education, 16(2), 7-17.

Joyce, B., \& Showers, B. (2002). Student achievement through staff development. Association for Supervision and Curriculum Development: Alexandria, VA.

Kilanowski-Press, L., Foote, C. J., \& Rinaldo, V. J. (2010). Inclusion classrooms and teachers: A survey of current practices. International Journal of Special Education, 25(3), 43-56.

Klasson, R. M., Tze, V. M., Betts, S. M., \& Gordon, K. A. (2011). Teacher efficacy research 1998-2009: Signs of progress of unfulfilled promise? Educational Psychology Review, 23, 21-43. 
Klingner, J. K., Vaughn, S., Hughes, M. T., Schumm, J. S., \& Elbaum, B. (1998). Outcomes for students with and without learning disabilities in inclusive classrooms. Learning Disabilities Research \& Practice, 13, 153-161.

Koegh, B. K. (2007). Celebrating PL 94-142: The Education of All Handicapped Children Act of 1975. Issues in Teacher Education, 16, 65-69.

Kosko, K., \& Wilkins, J. (2009). General educator's in-service training and their selfperceived ability to adapt instruction for students with IEPs. The Professional Education, 33(2), 1-10.

Labone, E. (2004). Teacher efficacy: Maturing construct through research in alternate paradigms. Teaching and Teacher Education, 20, 341-359.

Lamport, M., Graves, L., \& Ward, A. (2012). Special needs students in inclusive classrooms: The impact of social interaction on educational outcomes for learners with emotional and behavioral disabilities. European Journal of Business and Social Sciences, 1(5), 54-69.

McLeskey, J., Henry, D., \& Hodges, D. (1999). Inclusion: What progress is being made across disability categories? Teaching Exceptional Children, 31(3) 60-64.

McLeskey, J., \& Waldron, N. L. (2011). Educational programs for elementary students with learning disabilities: Can they be both effective and inclusive? Learning Disabilities Research \& Practice, 26(1), 48-57.

Martin, E. W., Martin, R., \& Terman, D. L. (1996). The legislative and litigation history of special education. Special Education for Children with Disabilities, 6(1), 2539. 
Meyer, L. (2001). The impact of inclusion on children's lives: Multiple outcomes, and friendship in particular. International Journal of Disability, Development and Education, 48, 9-31.

Moore, C., Gilbreath, D., \& Maiuri, F. (1998). Educating students with disabilities in the general education classrooms: A summary of the research. Washington, DC: U. S. Department of Education, Office of Special Education and Rehabilitative Services

No Child Left Behind Act of 2001, Pub. L. No. 107-110, 115 Stat. 1425 (2002).

Obiakor, F. (2011). Maximizing access, equity, and inclusion in general and special education. The Journal of International Association of Special Education, 12(1), $10-16$.

Odum, S., Buyusse, V., \& Soukakou, E. (2011). Inclusion of young children with disabilities: A quarter century of research prospectives. Journal of Early Intervention, $33,344-356$.

Putnam, S. M. (2012). Investigating teacher efficacy: Comparing pre-service and inservice teachers with different levels of experience. Action in Teacher Education, $34,26-40$.

Rea, P. J., McLaughlin, V. L., \& Walther-Thomas, C. (2002). Outcomes for student with learning disabilities in inclusive and pullout programs. Exceptional Children, 68, 203-223.

Ross, J., \& Bruce, C. (2007). Professional development effects on teacher efficacy: Results of randomized field trial. The Journal of Educational Research, 101, 5059. 
Rotter, J. B. (1966). Generalized expectancies for internal versus external control of reinforcement. Psychological Monographs: General and Applied, 80, 1-28.

Ruef, M. B. (2003). Including students with disabilities: Let's move forward together. Action in Teacher Education, 25(1), 1-4.

Sailor, W. (1991). Special education in a restructured school. Remedial and Special Education, 12(6), 8-22.

Salisbury, C., Strieker, T., Roach, V., \& McGregor, G. (2001). Pathways to inclusive practices: Systems-oriented, policy-linked, and research-based strategies that work. Alexandria, VA: Consortium on Inclusive Schooling Practices; Chicago, IL: Erikson Institute for Advanced Study in Child Development; Washington, DC: Special Education Programs (ES/OSERS)

Scruggs, T. E., \& Mastropieri, M. A. (1996). Teacher perceptions of mainstreaming/inclusion, 1958-1995: A research synthesis. Exceptional Children, 63, 59-74.

Shippen, M. E., Flores, M. M., Crites, S. A., Patterson, D., Ramsey, M. L., Houchins, D. E., \& Jolivette, K. (2011). Classroom structure and teacher efficacy in serving students with disabilities: Differences in elementary and secondary teachers. International Journal of Special Education, 26(3), 36-44.

Smith, D. D., \& Tyler, N. C. (2011). Effective inclusion education: Equipping education professionals with necessary skills and knowledge. Prospects, 41, 323-339.

Soodak, L. C., \& Podell, D. M. (1993). Teacher efficacy and student problems as factors in special education referral. Journal of Special Education, 27, 66-81. 
Soodak, L. C., Podell, D. M., \& Lehman, L. R. (1998). Teacher, student and school attributes as predictors of teachers' responses to inclusion. The Journal of Special Education, 31, 480-497.

Swackhamer, L.E., Koellner, K., Basile, C., \& Kinbrough, D. (2009). Increasing the selfefficacy of in-service teachers through content knowledge. Teacher Education Quarterly, 36(2), 63-78.

Thurlow, M. L., Lazarus, S. S., Thompson, S. J., \& Morse, A. B. (2005). State policies on assessment participation and accommodations for students with disabilities. The Journal of Special Education, 38, 232-240.

Tschannen-Moran, M., Woolfolk Hoy, A., \& Hoy, W. K. (1998) Teacher efficacy: Its meaning and measure. Review of Educational Research, 68, 202-248.

Tschannen-Moran, M. \& Woolfolk Hoy, A. (2001). Teacher efficacy: Capturing an elusive construct. Teaching and Teacher Education, 17, 783-805.

Tschannen-Moran, M. \& Woolfolk Hoy, A. (2006). The differential antecedents of selfefficacy beliefs of novice and experienced teachers. Teaching and Teacher Education, 23, 944-956.

U.S. Department of Education, Office of Special Education and Rehabilitative Services (2010). Thirty-five years of progress in educating children with disabilities through IDEA. Washington, DC: U.S. Government Printing Office.

Wentzel, K. R., \& Wigfield, A. (1998). Academic and social motivational influences on students' academic performance. Educational Psychology Review, 10, 155-175. 
Whitley, J. (2010). Modeling the influence of teacher characteristics on student achievement for Canadian students with and without learning disabilities. International Journal of Special Education, 25(3), 88-97.

Yellin, P. G., Yellin, D., Claypool, P. L., Mokhtari, K., Carr, R., Latiker, T., \& Szabo, S. (2003). I'm not sure I can handle the kids, especially, the, uh, you know special ed kids. Action Teacher Education, 25, 14-18.

Ysseldyke, J., Thurlow, M., Christenson, S., \& McVicar, R. (1988). Instructional grouping arrangements used with mentally retarded, learning disabled, emotionally disturbed, and non-handicapped elementary students. Journal of Educational Research, 81, 305-311.

Zigmond, N. (2003). Where should students with disabilities receive special education services: Is one place better than another? The Journal of Special Education, 37, 193-199. 


\section{Appendices}

\section{Appendix A}

Teacher Efficacy Scale (Gibson \& Dembo, 1984)*

Please indicate the degree to which you agree or disagree with each statement below by circling the appropriate numeral to the right of each statement. When answering each question, reflect on the students with disabilities in your class.

$$
\begin{aligned}
& 6=\text { Strongly agree } \\
& 5=\text { Moderately agree } \\
& 4=\text { Agree slightly more than disagree } \\
& 3=\text { Disagree more slightly than agree } \\
& 2=\text { Moderately disagree } \\
& 1=\text { Strongly disagree }
\end{aligned}
$$

$\begin{aligned} & \text { 1. When a student with disabilities does } \\ & \text { better than usual, many times it is because I } \\ & \text { exerted a little extra effort. }\end{aligned}$
$\begin{aligned} & \text { 2. The hours in my class have little } \\ & \text { influence on students with disabilities } \\ & \text { compared to the influence of their home } \\ & \text { environment. }\end{aligned}$




\begin{tabular}{|c|c|c|c|c|c|c|}
\hline $\begin{array}{l}\text { 8. A teacher is very limited in what he/she } \\
\text { can achieve because a student with } \\
\text { disabilities' home environment is a large } \\
\text { influence on his/her achievement. }\end{array}$ & 1 & 2 & 3 & 4 & 5 & 6 \\
\hline $\begin{array}{l}\text { 9. When the grades of my students with } \\
\text { disabilities improve it is usually because I } \\
\text { found more effective teaching approaches. }\end{array}$ & 1 & 2 & 3 & 4 & 5 & 6 \\
\hline $\begin{array}{l}\text { 10. If a student with disabilities masters a } \\
\text { new math concept quickly, this might be } \\
\text { because I knew the necessary steps in } \\
\text { teaching that concept. }\end{array}$ & 1 & 2 & 3 & 4 & 5 & 6 \\
\hline $\begin{array}{l}\text { 11. If parents would do more with their } \\
\text { children with disabilities, I could do more. }\end{array}$ & 1 & 2 & 3 & 4 & 5 & 6 \\
\hline $\begin{array}{l}\text { 12. If a student with disabilities did not } \\
\text { remember information I gave in a previous } \\
\text { lesson, I would know how to increase } \\
\text { her/his retention in the next lesson. }\end{array}$ & 1 & 2 & 3 & 4 & 5 & 6 \\
\hline $\begin{array}{l}\text { 13. If student with disabilities in my class } \\
\text { becomes disruptive and noisy, I feel assured } \\
\text { that I know some techniques to redirect him } \\
\text { quickly. }\end{array}$ & 1 & 2 & 3 & 4 & 5 & 6 \\
\hline $\begin{array}{l}\text { 14. The influences of a student with } \\
\text { disabilities' home environment can be } \\
\text { overcome by good teaching. }\end{array}$ & 1 & 2 & 3 & 4 & 5 & 6 \\
\hline $\begin{array}{l}\text { 15. If one of my students with disabilities } \\
\text { could not do a class assignment, I would be } \\
\text { able to accurately assess whether the } \\
\text { assignment was at the correct level of } \\
\text { difficulty. }\end{array}$ & 1 & 2 & 3 & 4 & 5 & 6 \\
\hline $\begin{array}{l}\text { 16. Even a teacher with good teaching } \\
\text { abilities may not reach many students with } \\
\text { disabilities. }\end{array}$ & 1 & 2 & 3 & 4 & & 6 \\
\hline
\end{tabular}

*Amended efficacy scale to address students with disabilities 


\section{Appendix B}

\section{Questions Measuring Experiences Based on Bandura's Sources of Efficacy}

Directions: Please reflect on the experiences you have had in the last 10 years that fall into each of the given categories.

$1=$ Never (No experiences per year) $4=$ Frequently (Three to four experiences per year)

\section{Mastery Experiences}

When a teacher experiences success with a student with a disability, or with a lesson, they have a mastery experience. This type of mastery experience gives them increased confidence in their own instructional practice and abilities. A mastery experience gives a teacher confidence to use those same instructional and classroom management skills again when presented with another challenge.

To what extent have you had mastery experiences with students with disabilities?

$\begin{array}{llll}1 & 2 & 3 & 4\end{array}$

\section{Vicarious Experiences}

Vicarious experiences are those in which one teacher observes another experiencing success. Some examples of professional development vicarious experiences include collaborative learning visits, sharing and discussion of student work within Collaborative Learning Teams, watching a video of another teacher teaching, and watching and evaluating a video of yourself teaching. Teachers can develop increased competency in their own instructional practice and classroom management skills when they observe another modeling successful practice with students with disabilities.

To what extent have you participated in these types of professional development vicarious experiences?

$\begin{array}{llll}1 & 2 & 3 & 4\end{array}$




\title{
Social Persuasion
}

Social persuasion experiences are those activities that involve encouragement and performance feedback from a supervisor or a colleague. Some examples of social persuasion experiences include peer coaching (two teachers observe one another and engage in non-evaluative feedback with one another) and participation in a study group which collaboratively examines current research. Additional course work and professional development training about students with disabilities are also examples of social persuasion experiences. Social persuasion experiences can help teachers improve their knowledge base and, consequently their instructional practice and classroom management skills with student with disabilities.

To what extent have you participated in these types of professional development social persuasion experiences?

$\begin{array}{llll}1 & 2 & 3 & 4\end{array}$

\begin{abstract}
Affective State
Affective state is your level of anxiety or excitement experienced in different situations. Calming self-talk or seeking the comfort of social support are examples of how you may impact your affective state. When teachers have increased levels of anxiety or excitement, this can affect their perceptions of their own capabilities or competence when working with students with disabilities.
\end{abstract}

To what extent are you aware that your affective state has impacted your beliefs in your personal competency to work with students with disabilities?

$\begin{array}{llll}1 & 2 & 3 & 4\end{array}$ 


\section{Appendix C}

\section{Demographic Data}

In the last ten years, how many years have you had students with disabilities in your class? 


\section{Appendix D}

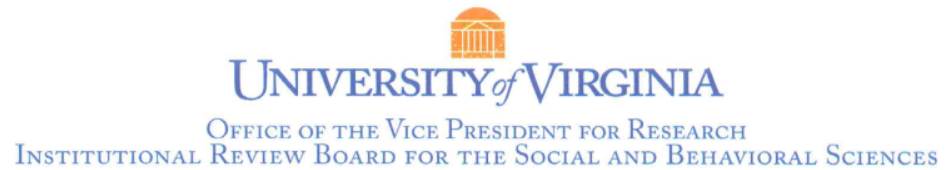

In reply, please refer to: Project \# 2013-0471-00

January 6, 2014

Elizabeth Beaty and Dennise Berry

Leadership, Foundations \& Policy

5399 Sequoia Farms Dr.

Centreville, VA 20120

Dear Elizabeth Beaty and Dennise Berry:

Thank you for submitting your project entitled: "Experiences and General Education Teachers' Sense of Efficacy Concerning Students with Disabilities" for review by the Institutional Review Board for the Social \& Behavioral Sciences. The Board reviewed your Protocol on January 6 , 2014.

The first action that the Board takes with a new project is to decide whether the project is exempt from a more detailed review by the Board because the project may fall into one of the categories of research described as "exempt" in the Code of Federal Regulations. Since the Board, and not individual researchers, is authorized to classify a project as exempt, we requested that you submit the materials describing your project so that we could make this initial decision.

As a result of this request, we have reviewed your project and classified it as exempt from further review by the Board for a period of four years. This means that you may conduct the study as planned and you are not required to submit requests for continuation until the end of the fourth year. I

This project \# 2013-0471-00 has been exempted for the period January 6, 2014 to January 5, 2018. If the study continues beyond the approval period, you will need to submit a continuation request to the Board. If you make changes in the study, you will need to notify the Board of the changes.

Sincerely,

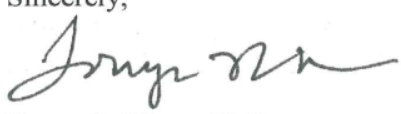

Tonya R. Moon, Ph.D.

Chair, Institutional Review Board for the Social and Behavioral Sciences

$$
\begin{gathered}
\text { One Morton Drive, Suite } 500 \text { • Charlottesville, VA } 22903 \\
\text { P.O. Box 800392 • Charlottesville, VA 22908-0392 } \\
\text { Phone: 434-924-5999 • Fax: 434-924-1992 } \\
\text { www.virginia.edu/vpr/irb/sbs.html }
\end{gathered}
$$




\section{Appendix E}

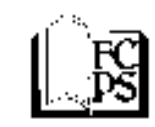

FAIRFAX COUNTY PUBLIC SCHOOLS
Department of Professional Learning and Accountability

3877 Fairfax Ridge Road

Fairfax, Virginia 22030-7425

April 2, 2014

Elizabeth Beaty

5399 Sequoia Farms Drive

Centreville, VA 20120

Dear Ms. Beaty:

The Research Screening Committee has reviewed and approved, with conditions, your application to conduct a study entitled Experiences and General Education Teacher's Efficacy Concerning Students with Disabilities. The conditions of approval for this study are listed on the attached Research Approval Agreement enclosed with this letter. The division places great trust in you to maintain the highest standards for research, to comply with all of the specified conditions of approval, and to seek counsel from your sponsor if the conditions are ever in jeopardy. Kim Dockery, assistant superintendent, Department of Special Services, has agreed to be your sponsor. Please call her at 571-423-4010 to begin the project.

You may begin the study as soon as you complete and return the enclosed Research Approval Agreement. We look forward to receiving the study results which will inform FCPS about how different types of professional development experiences relate to teacher efficacy with special education students.

\section{Sincerely,}

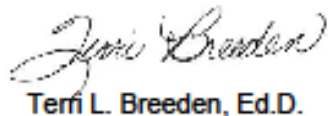

Assistant Superintendent

TLB/am

Enclosure

cc: Kim Dockery 